\title{
Phase II Nuclide Partition Laboratory Study Influence of Cellulose Degradation Products on the Transport of Nuclides from SRS Shallow Land Burial Facilities
}

by

S. M. Serkiz

Westinghouse Savannah River Company

Savannah River Site

Aiken, South Carolina 29808

D. Knaub

Clemson University

c. Lee

Clemson University

DOE Contract No. DE-AC09-96SR18500

This paper was prepared in connection with work done under the above contract number with the U. S. Department of Energy. By acceptance of this paper, the publisher and/or recipient acknowledges the U.S. Government's right to retain a nonexclusive, royalty-free license in and to any copyright covering this paper, along with the right to reproduce and to authorize others to reproduce all or part of the copyrighted paper. 


\section{DISCLAIMER}

This report was prepared as an account of work sponsored by an agency of the United States Government. Neither the United States Government nor any agency thereof, nor any of their employees, makes any warranty, express or implied, or assumes any legal liability or responsibility for the accuracy, completeness, or usefulness of any information, apparatus, product, or process disclosed, or represents that its use would not infringe privately owned rights. Reference herein to any specific commercial product, process, or service by trade name, trademark, manufacturer, or otherwise does not necessarily constitute or imply its endorsement, recommendation, or favoring by the United States Government or any agency thereof. The views and opinions of authors expressed herein do not necessarily state or reflect those of the United States Government or any agency thereof.

This report has been reproduced directly from the best available copy.

Available to DOE and DOE contractors from the Office of Scientific and Technical Information, P.O. Box 62, Oak Ridge, TN 37831; prices available from (615) 576-8401.

Available to the public from the National Technical Information Service, U.S. Department of Commerce, 5285 Port Royal Road, Springfield, VA 22161. 


\section{DISCLAIMER}

Portions of this document may be illegible in electronic image products. Images are produced from the best available original document. 


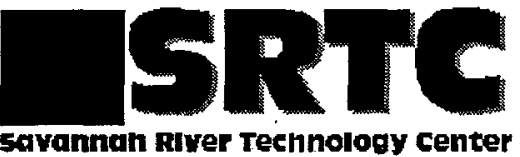

WSRC-TR-99-00298-TL

August 30, 1999

TO: $\quad$ W. T. Goldston, 703-5C

FROM: $\quad$ B. T. Butcher, $773-43$ A $(x 5-5810)$

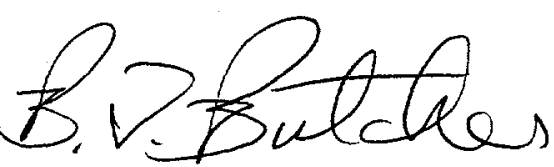

\section{TRANSMITTAL OF CELLULOSE DEGRADATION PRODUCTS STUDY REPORT (U)}

Attached is the report entitled, "Phase II Nuclide Partition Laboratory Study Influence of Cellulose Degradation Products on the Transport of Nuclides from SRS Shallow Land Burial Facilities (U)", WSRCTR-99-00298, prepared by Steve Serkiz of SRTC. This report is being submitted to satisfy the LLW AOP Expectations and Definitions of Success established between DOE-SR and Solid Waste to "Develop Kd factors for Organic Material compounds under site leaching conditions" by 8/30/99.

Att.

$\mathrm{CC}:(\mathrm{w} / \mathrm{Att})$

P. I. Hudson, 705-3C

R. M. Seaborn, 705-3C

H. Holmes-Burns, 724-9E

M. W. Lewis, 724-7E

N. S. Roddy, 724-15E

D. F. Sink, 724-15E

L. C. Thomas, 724-7E

D. J. Swale, 724-7E

W. E. Stevens, 773-A

B. T. Butcher, 773-43A

L. B. Collard, 773-43A

J. R. Cook, 773-43A

E. L. Wilhite, $773-43 \mathrm{~A}$

S. M. Serkiz, 773-A

D. I. Kaplan, 773-43A

C. A. Langton, $773-43 \mathrm{~A}$

L. N. Oji, 773-43A

N. C. Bell, 773-A

STL 6 , 703.43A

WPT File, 773-43A 
Keywords: Radionuclide Speciation and Transport, Cellulose Degradation, Dissolved Organic Matter, Europium, Uranium, E-Area Vaults, Performance Assessment

Retention: Permanent

Phase II Nuclide Partition Laboratory Study Influence of Cellulose Degradation Products

On the Transport of Nuclides from SRS Shallow Land Burial Facilities (U)

S. M. Serkiz, Waste Processing Technology SRTC, Building 773A

D. Knaub and C. Lee, Environmental Engineering and Science Dept. Clemson University 
WSRC-TR-99-00298

Revision 0

Keywords: Radionuclide Speciation and Transport, Cellulose Degradation, Dissolved Organic Matter, Europium, Uranium, E-Area Vaults, Performance Assessment

Retention: Permanent

Phase II Nuclide Partition Laboratory Study Influence of Cellulose Degradation Products On the Transport of Nuclides from SRS Shallow Land Burial Facilities (U)

S. M. Serkiz, Waste Processing Technology, SRTC, Building 773A

D. Knaub and C. Lee, Environmental Engineering and Science Dept. Clemson University

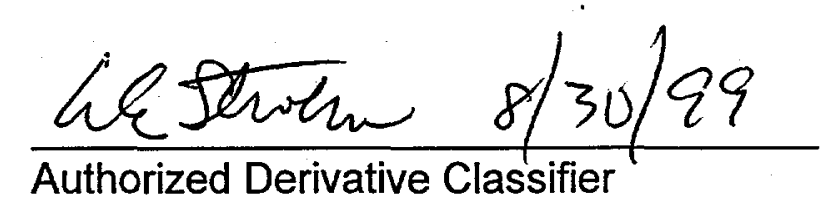

Savannah River Technology Center Westinghouse Savannah River Company Aiken, SC 29808 


\section{Authors}

Stweng. Sevei $\quad 8 / 30 / 99$

S. M. Serklz. Waste Disposal \& Envirohmental Development Date 14avit Delnauls_ $8 / 30 / 99$

D. Knaub. Environmentál Eng. \& Science Dept. - Clemson University Date

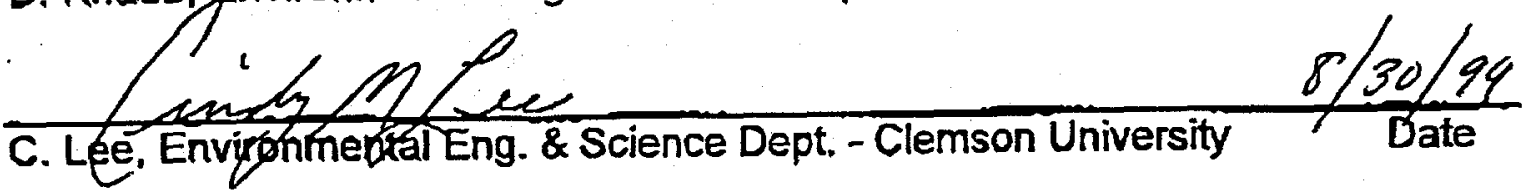

\section{Design Check}

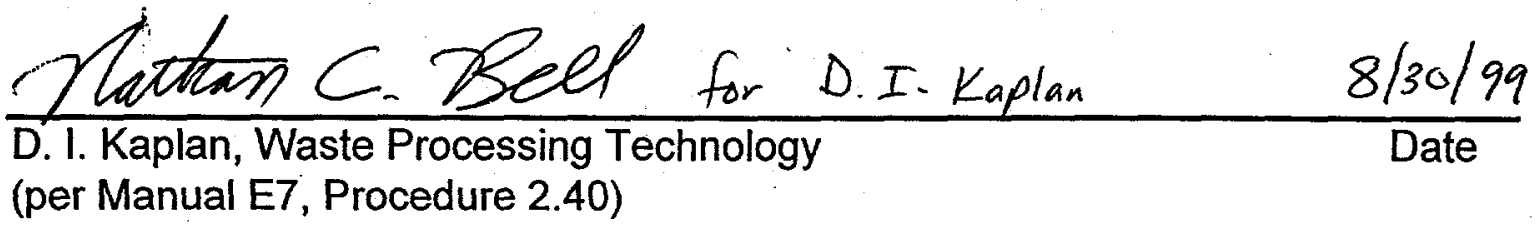

\section{Approvals}

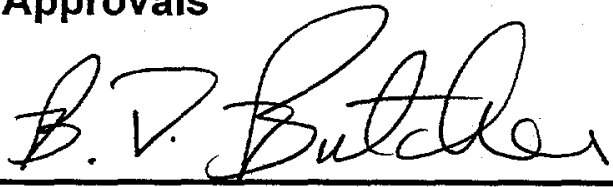

B. T. Butcher, Level 4 Manager

Waste Disposal \& Environmental Development - SRTC 


\section{TABLE OF CONTENTS}

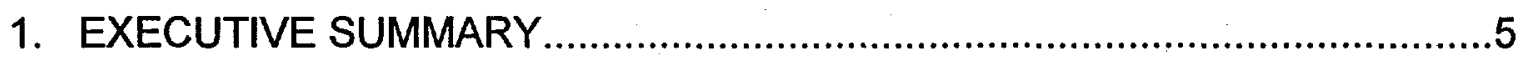

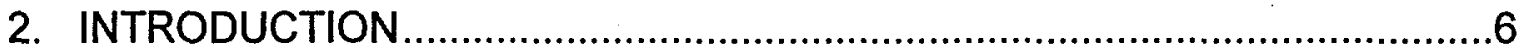

2.1. Previous Performance Assessment Modeling of CDP ...........................7

2.2. Objectives of Validation Studies............................................................8

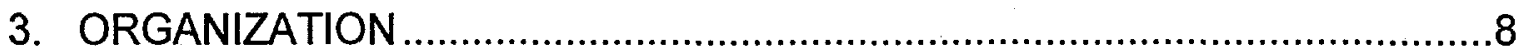

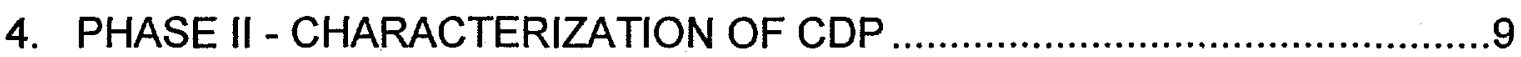

4.1. Purpose and Approach - Characterization of CDP ..................................

4.2. Previous Work - Characterization of CDP .........................................10

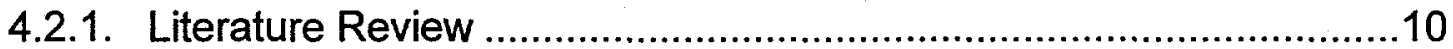



4.3. Materials and Methods - Characterization of CDP ...............................14

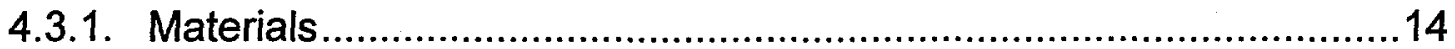

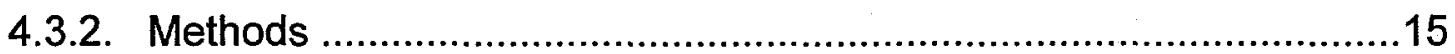

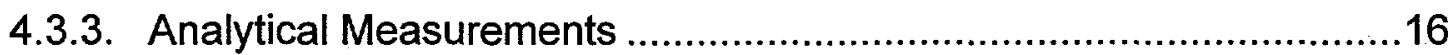

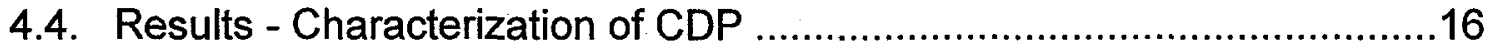

4.5. Conclusions - Characterization of CDP ..............................................17

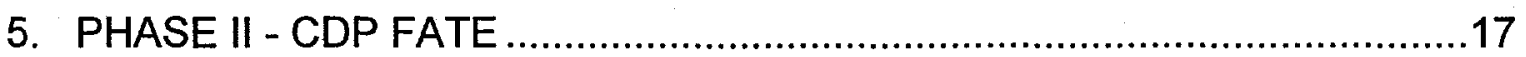

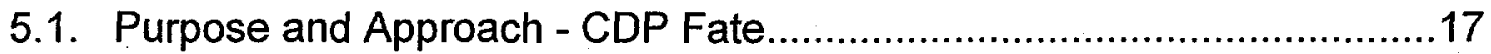

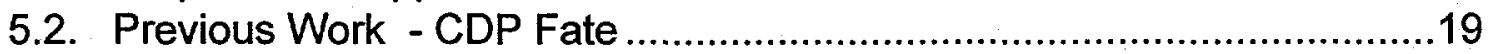



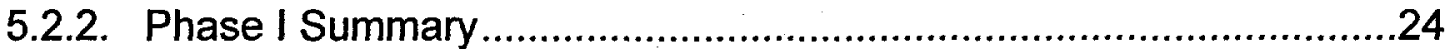

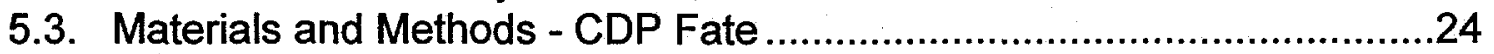

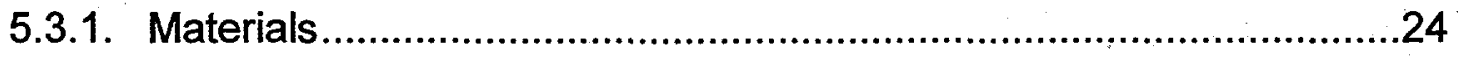

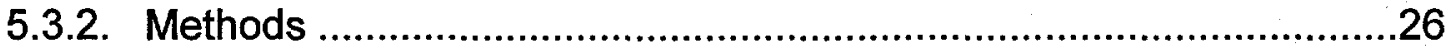

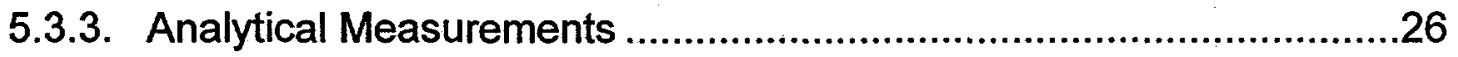

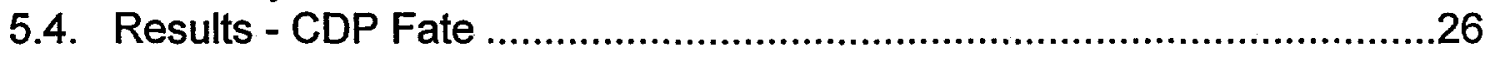

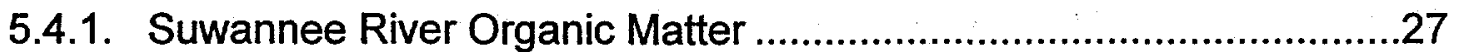

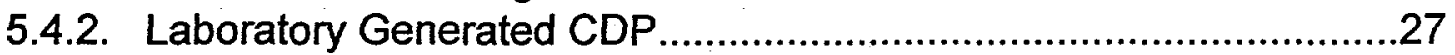

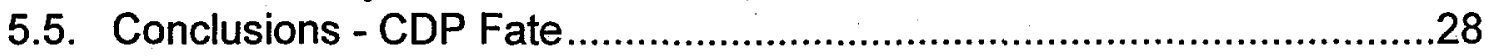

6. PHASE II - RADIONUCLIDE PARTITIONING STUDIES ..........................29.

6.1. Purpose and Approach - Radionuclide Partitioning Studies...................29

6.2. Previous Work - Radionuclide Partitioning Studies ...............................30

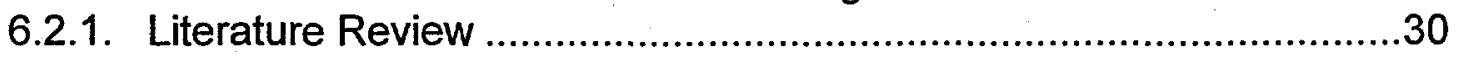

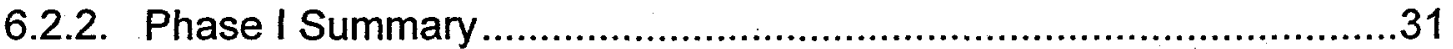

6.3. Materials and Methods - Radionuclide Partitioning Studies ...................32

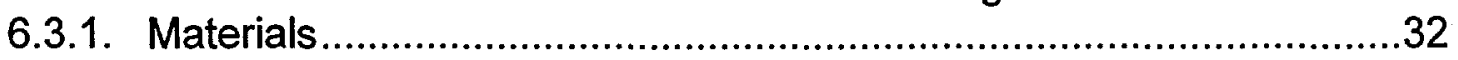

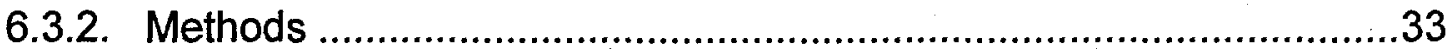

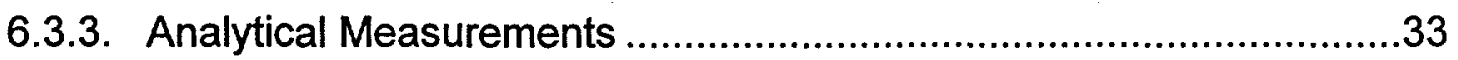

6.4. Results - Radionuclide Partitioning Studies ......................................34 
6.4.1. Organic Matter Concentration .......................................................34



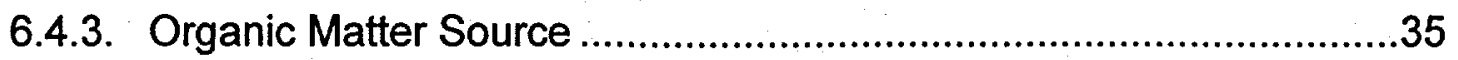

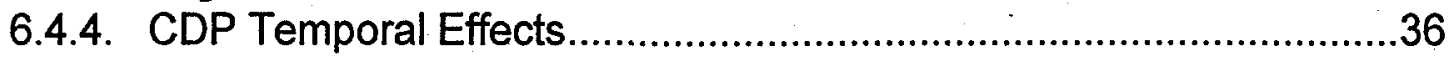

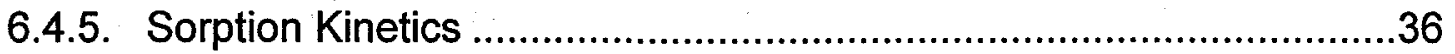

6.5. Conclusions - Radionuclide Partitioning Studies .....................................36

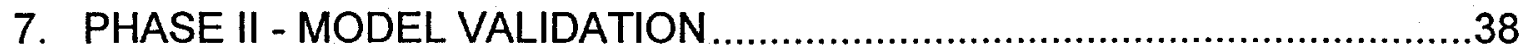

7.1. Purpose and Approach - Model Validation ..........................................38



7.3. Results and Conclusions - Model Validation ........................................38

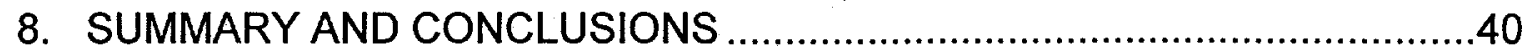

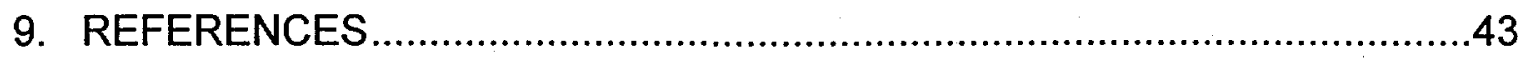

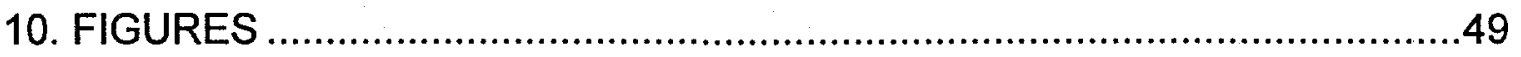




\section{Executive Summary}

Degradation products of cellulosic materials (e.g., paper and wood products) can significantly influence the subsurface transport of metals and radionuclides. Codisposal of radionuclides with cellulosic materials in the E-Area slit trenches at the SRS is, therefore, expected to influence nuclide fate and transport in the subsurface. Due to the complexities of these systems and the scarcity of site-specific data, the effects of cellulose waste loading and its subsequent influence on nuclide transport are not well established.

Modeling of this system was undertaken in 1996. This initial modeling used published stability constants for reactions between low molecular weight acids (i.e., citric acid and EDTA) and numerous radionuclides to approximate behavior of CDP. Notable differences in the allowable radionuclide inventory of the EArea slit trench were determined when the presence of cellulose degradation products (CDP) was accounted for in this conceptual model. Results of modeling are documented in an earlier report (Serkiz and Myers, 1996).

A series of laboratory studies were initiated in April 1998 to validate and/or update the modeling assumptions and results utilizing uranium (VI) and europium (III) as representative of divalent and trivalent radionuclides in the disposal environment. Phase I of this work employed a surrogate organic matter (OM) collected from the Suwannee River to represent the influence of CDP on nuclide sorption. This natural OM has been extensively characterized and is believed to resemble more closely the products from the degradation of cellulosic material than any single organic compound. These studies clearly demonstrated that both $\mathrm{pH}$ and organic matter have a significant influence on europium and uranium mobility in SRS shallow waste burial environments. Phase I results are documented in an earlier report (Serkiz et al., 1998).

Phase II of this work, the subject of this report, investigated the major processes that influence nuclide transport in the presence of CDP. These parameters included; 1) the effect of CDP characteristics, i.e., natural OM versus laboratory generated CDP, 2) CDP fate, specifically, sorption of CDP to SRS soils and, 3) nuclide partitioning in the presence of CDP under a range of $\mathrm{pH}$ conditions. This work demonstrated that natural OM from the Suwannee River is an adequate surrogate for the nuclide complexation chemistry of the mixture of organic compounds that comprise CDP under the conditions expected in SRS trenches. Furthermore, CDP production was shown to be time-dependent with production rates decreasing as a function of increased leaching time. Evidence was found that CDP are sorbed by SRS soils with the fraction sorbed dependent on initial concentration of $\mathrm{OM}$ but relatively independent of $\mathrm{pH}$. However, $\mathrm{pH}$ was 
confirmed to be a major determinant in the sorption of Eu to SRS soils in the presence or absence of CDP.

In previous modeling work it was assumed that cellulose materials degrade to constantly produce dissolved $\mathrm{OM}$ at $30 \mathrm{mg}$ carbon/L. It is clear from this laboratory work that the production of CDP is a dynamic process with concentrations over $1,000 \mathrm{mg} \mathrm{C} / \mathrm{l}$ having been observed. Previous modeling also assumed a single $\mathrm{pH}$ value for the natural background to estimate contaminant sorption. Modeling in the next phase should incorporate the observed $\mathrm{pH}$ depression resulting from the cellulose degradation process.

The final phase of work will be to incorporate the factors described above, as appropriate, into the previous conceptual model and to issue a report with revised $K_{d}$ values. If $K_{d}$ values are significantly different than those previously used, the current PA special analysis for wood products in the E-Area slit trenches will be updated with these new values.

\section{Introduction}

Cellulosic materials (e.g., wood and paper products) readily degrade in the environment to form cellulose degradation products (CDP) in both the solid and dissolved (i.e., dissolved organic carbon (DOC)) phases. The influence of natural organic matter (NOM) on the speciation (i.e., chemical form) and mobility of nonradioactive elements (Perdue and Gjessing, 1990; Thurman; 1985; and Stumm and Morgan, 1981) and radioactive elements (Choppin 1988; Allard et al. 1989; Fairhurst et al. 1995; and Ledin et al. 1994) is well documented in the open literature. Co-disposal of radionuclides with cellulosic materials is, therefore, expected to influence nuclide fate and transport in the subsurface. The disposal and degradation of wood products in the E-Area slit trenches at the SRS are a source of OM that is expected to influence radionuclide fate.

Insights into the fate of cellulosic material in SRS burial trenches can be drawn from the extensively studied behavior of NOM in forested ecosystems. In both of these environments cellulosic materials are expected to decay to form a complex mixture of natural organic acids (e.g., humic and fulvic acids). These organic acids in forested ecosystems make up the majority of naturally occurring soil and dissolved organic matter (Thurman, 1985). Even though this OM will ultimately degrade to $\mathrm{CO}_{2}$ or methane, steady state dissolved organic carbon concentrations in soil porewater resulting from tree and leaf litter decay processes can be as high as several hundred $\mathrm{mg}$ Carbon (C)/L (Thurman, 1985). As an example, a typical soil profile is shown in Figure 1.

The complexities of the OM cycle are illustrated in Figure 1. The major processes that influence organic matter fate and transport in near surface 
systems include; (1) DOC production from cellulose degradation and leaching, (2) metal/nuclide complexation with DOC, (3) sorption of organic matter to soil surfaces, and (4) mineralization of organic matter by soil microbes. Some of these processes act to enhance metal/nuclide transport while others act to inhibit their transport. In the SRS slit trenches the dominant processes are not known. Modeling results (Serkiz and Myers, 1996), however, suggest that the dissolved fraction of these CDP will form complexes with radionuclides, reducing radionuclide sorption to soil surfaces, and, thereby, increasing their mobility.

\subsection{Previous Performance Assessment Modeling of CDP}

A modeling exercise (Serkiz and Myers, 1996) was undertaken to estimate the influences of the co-disposal of wood products on the inventory limits of various radionuclides in the E-Area slit trenches. A number of assumptions were required to complete this modeling exercise. These assumptions included:

- citric acid or ethylenedinitrilotetraacetic acid (EDTA) are adequate surrogates for the nuclide complexation chemistry of the mixture of organic compounds that comprise cellulose degradation products;

- a linear sorption isotherm (i.e., a $\mathrm{K}_{d}$ ) approach, as used in the performance assessment modeling (MMES, 1994), is adequate to describe nuclide partitioning to soil surfaces as a function of changing trench geochemical conditions; and

- aqueous organic matter concentration derived from cellulose degradation was $30 \mathrm{mg} \mathrm{C/L}$ and exhibits no temporal variations.

Using this modeling approach, OM generated from cellulose degradation was predicted to have no effect on the inventory limits for $\mathrm{Cs}, \mathrm{Np}, \mathrm{Rb}$ and $\mathrm{Zr}$. The inventory limits for the isotopes of $\mathrm{Am}, \mathrm{Cf}, \mathrm{Cm}, \mathrm{Bk}, \mathrm{Ni}, \mathrm{Pd}, \mathrm{Pu}, \mathrm{Sr}$, and $\mathrm{U}$ calculated in the presence of this $\mathrm{OM}$ were predicted to decrease over a range of 26 percent for $\mathrm{U}-233$ to 48 percent for $\mathrm{Pu}-240$ from previous model predictions. The details of this modeling effort are documented in Serkiz and Myers (1996). These calculations provided important first approximations of radionuclide mobility in various scenarios, however, the underlying assumptions require validation. 


\subsection{Objectives of Validation Studies}

Validation studies were undertaken to investigate major processes that influence nuclide transport in the presence of CDP; the affects of 1) CDP character, 2) CDP fate, and 3) nuclide partitioning in the presence of CDP. More specifically, four research areas were investigated during each study phase as follows:

Characterization of CDP.

- Phase I - development of CDP organic surrogate from existing data.

- Phase II-cellulose leaching study to collect data on the rate of formation and character of degradation products.

- Phase III - validate or update current model with laboratory data.

CDP Fate.

- Phase I-sorption of CDP organic surrogate to SRS soils and SRS reactive mineral surfaces.

- Phase II-sorption of CDP to SRS soils, collect cellulose degradation rate data.

- Phase III - validate or update current model with laboratory data.

Radionuclide Partitioning Studies

- Phase I-CDP Surrogate Study

- pH effects ( 3 to10)

- affect of CDP surrogate concentration

- nuclide valence effect $\left(\mathrm{UO}_{2}{ }^{2+}\right.$ and $\left.\mathrm{Eu}^{3+}\right)$.

- Phase II - Laboratory Generated CDP Study

- pH effects (3 to10)

- affect of CDP concentration

- Phase III - validate or update current model with laboratory data.

Model Validation/Trench Limit Update

- Phase I - comparison of CDP organic surrogate data with current model assumptions.

- Phase II - comparison of CDP data with surrogate data and current model assumptions.

- Phase III - validate or update current model and, if necessary, recalculate trench limits.

\section{Organization}

The remainder of this report is organized around the four general topic areas Characterization of CDP (Section 4), CDP Fate (Section 5), Radionuclide Partitioning Studies (Section 6), and Model Validation/Trench Limit Update 
(Section 7) described above. Overall Phase II conclusions and summary are presented in Section 8.

\section{Phase II - Characterization of CDP}

\subsection{Purpose and Approach - Characterization of CDP}

The purpose of this CDP characterization effort was to (1) compare the chemical characteristics of CDP with those of natural system analogues (e.g., NOM from forested ecosystems and surface waters); (2) investigate the relationship between CDP character and its influence on lanthanide/actinide mobility; and (3) evaluate the temporal changes in quantity and character of CDP generated from cellulosic materials known to be present in the SRS slit trenches. These data will subsequently be used to validate and/or update the existing model used to set radionuclide inventories for shallow trench disposal environments in the presence of these cellulosic materials.

Because much data exist on the chemistry of NOM in the environment, the use of these data for modeling CDP in SRS shallow trench systems would be greatly facilitated if CDP organic matter is chemically similar to that of NOM or a relationship between the chemical characteristics of CDP and that of NOM can be developed. An understanding of the affect NOM character on lanthanide/actinide mobility would allow the development of a more technically defensible and predictive model that could account for changes in organic matter quality that are expected to occur both spatially and temporally. CDP generation rates are an input to the model for this system and, therefore, these data will be used to validate or update this model-input parameter. Furthermore, because the cellulosic degradation process is known to influence subsurface geochemistry (e.g., lowering $\mathrm{pH}$ ), a characterization of the major ion chemistry associated with the degradation of cellulosic materials is necessary to more accurately model the affect of these materials on subsurface geochemistry and, hence, nuclide mobility.

The approach of this Phase II laboratory study was to generate and characterize CDP from a mixture of solid cellulosic materials know to be present in SRS waste trenches. A portion of the aqueous phase was collected at selected time intervals. These aqueous samples were then analyzed for total organic carbon content and $\mathrm{pH}$. CDP samples from selected points in time were further utilized in the subsequent Phase II experiments described below to evaluate the CDP fate and its influence on nuclide partitioning. 


\subsection{Previous Work - Characterization of CDP}

\subsubsection{Literature Review}

\subsubsection{Background}

Investigation into the sorption behavior of europium in the presence of CDP requires the identification of the relevant controlling chemical reactions for organic matter cycling in near-surface systems. Because we have chosen the approach of using natural organic matter (NOM) as a surrogate for CDP generated in SRS trench disposal environments, an understanding of these controlling chemical reactions (e.g., sorption to soil surfaces and microbial degradation) should include an evaluation of the quantity and chemical quality of NOM native to the coastal plain region of the southeastern United States, characterization of the surrogate NOM, and characterization of the CDP.

The processes of cellulose degradation result in a complex mixture of compounds as shown by Serne et al. (1993). These researchers characterized CDP in leachate from paper and wood after twelve weeks of aging and were able to identify less than 4 percent of the total organic carbon as specific organic compounds. Furthermore, it has been shown that leaf litter (a cellulose based source material) leachate varies in character and quantity as a function of aging time, temperature, source material, and moisture content (Serkiz, 1991). When NOM degrades, a significant amount of the organic carbon remaining in solution is transformed into large molecules that contain aromatic rings, aliphatic chains, and carboxylic and phenolic functional groups (see Figure 2). This naturally occurring dissolved organic matter, like CDP, is a complex mixture of organic compounds that is dominated, on a molar basis, by oxygen containing functional groups.

\subsubsection{Concentration and Characterization of the NOM}

The potential for the production of large amounts of NOM in the forested ecosystems of the southeastern United States appears to be great given the number of blackwater rivers in the region. Blackwater is the term used to describe many of the coastal plain rivers that are dark in color due to the large loads of DOC. The southeastern United States has a long, productive growing season with abundant rainfall and mild winters. There is no spring flush due to melting snow but a relatively constant input of rainfall throughout the year that leads to high levels of organic decomposition (Malcolm et al., 1989). 
One example of a southeastern blackwater river is the Suwannee River that originates in the Okefenokee Swamp and flows through the coastal plain of Georgia and Florida to its outlet on the west coast of Florida. DOC concentrations are in excess of $25 \mathrm{mg} \mathrm{C/L}$ in the Suwannee (Malcolm et al., 1989a) with measurements in excess of $50 \mathrm{mg} \mathrm{C/L}$ for water collected near Fargo, GA (Serkiz and Perdue, 1991). The International Humic Substances Society (IHSS) selected the Suwannee River as the source for some of its reference humic and fulvic acids because it is representative of the blackwater rivers of the region and is relatively isolated yet accessible (Malcolm et al., 1989). We chose the Suwannee River DOC isolated by reverse osmosis and ion exchange (Serkiz and Perdue, 1991) as our surrogate NOM for the europium sorption experiments.

Although high concentrations of DOC exist in the surface waters, NOM in soil and groundwater will affect the sorption of radionuclides and heavy metals. With high levels of DOC in the surface waters of the Southeast, one would expect groundwater in the region to also have high concentrations. However, the survey of DOC levels in groundwater by Leenheer et al. (1974) found relatively low levels of DOC in the groundwaters of the southeastern US. Since 1974, few investigations have focused on the groundwater NOM of the Southeast. Two investigations of the DOC content of forested soil porewater in the region found a range with a high of $58 \mathrm{mg} \mathrm{C/L}$ in the OA horizon of a forest soil in the Coweeta Hydrologic Laboratory in the southern Appalachian Mountains of North Carolina (Qualls and Haines, 1991) and a low of $25.5 \mathrm{mg} \mathrm{C/L}$ under the A horizon of a forest soil on the coastal plain of South Carolina (Dosskey and Bertsch, 1997).

Qualls and Haines (1991) fractionated the DOC they collected from the forest soil horizons $(O A, A, A B, B$, and $C)$ into hydrophobic acids, hydrophilic acids, phenolic acids, hydrophobic neutrals, hydrophilic neutrals, and bases. The acids were dominated with the hydrophobic fraction as the largest percentage of the total DOC (>30 percent in most cases). The fractionation scheme employed by Qualls and Haines (1991) relied on differences in the surface properties solid phase at various $\mathrm{pH}$ values. Therefore, the hydrophobic versus hydrophilic distinction simply means that one fraction was protonated at $\mathrm{pH} 2$ making them hydrophobic and the other fraction was deprotonated or hydrophilic. At a higher $\mathrm{pH}$ both fractions would be deprotonated and hydrophilic. A small percentage of the hydrophobic acids were classified by Qualls and Haines (1991) as phenols but they attributed carboxylic acid functionalities to the vast majority of the acid fraction.

Dosskey and Bertsch (1997) collected soil water samples from a forested area of the Atlantic coastal plain at the Savannah River Site (SRS). They collected water from under the A soil horizon, in the E1 horizon, and under the E2 horizon. They did not fractionate the collected DOC but measured only total organic 
carbon. Dosskey and Bertsch (1997) reported the highest mean concentrations under the $A$ horizon $(25.5 \mathrm{mg} \mathrm{C/L})$ and in the throughfall $(35.0 \mathrm{mg} \mathrm{C/L})$ which is the rain coming through the forest canopy. As the soil porewater moved downward, they observed a decrease in the mean concentration of DOC with depth. At 76 to $99 \mathrm{~cm}$ below ground surface, Dosskey and Bertsch (1997) measured a mean concentration of $1.8 \mathrm{mg} \mathrm{C/L}$.

Reported groundwater concentrations for the region are also low. Dosskey and Bertsch (1997) observed DOC concentrations of $<1 \mathrm{mg} \mathrm{C} / \mathrm{L}$ in local groundwater from depths of 3 to $30 \mathrm{~m}$. McCarthy et al. (1993) measured DOC concentrations of 0.6 to $0.8 \mathrm{mg} \mathrm{C/L}$ for groundwater from a sandy, coastal plain aquifer at Clemson University's Baruch Forest Science Institute at Georgetown, SC. Size fractionation of the groundwater DOC by McCarthy et al. (1993) indicated that it was almost entirely less than 3000 molecular weight. At Coweeta Hydrologic Laboratory in NC, Qualls and Haines (1991) observed concentrations of 0.44 to $0.5 \mathrm{mg} \mathrm{C/L}$ in the $\mathrm{C}$ horizon. Therefore, groundwater levels of $\mathrm{DOC}$ are expected to be small in spite of the high concentrations in surface waters of the region.

\subsubsection{Characterization of the Surrogate NOM}

Natural organic matter is a complex mixture of large and small organic molecules derived from decomposing plants and animals that is difficult to fully characterize. As a standard and reference humic material for the IHSS, the Suwannee River fulvic and humic acids have been extensively studied (Averett et al., 1989). Based on the characterization, the sources of the material is hypothesized to be recent decomposition of vegetation within the Okenfenokee Swamp (Malcolm et al., 1989b). The characteristics of Suwannee River dissolved organic matter (SRDOM) of most interest for this investigation are its metals content and its acid functionalities.

SRDOM has very low concentrations of trace metals, less than $5 \mu \mathrm{g} / \mathrm{g}$ for all except Ag, Al, B, Ca, Fe, Mo, Na, Sn, Th, and $\mathrm{Zr}$ (Taylor and Garbarino, 1989). The multivalent metals that have higher concentrations are $\mathrm{Al}(\leq 30 \mu \mathrm{g} / \mathrm{g}$ fulvic acid, $\leq 200 \mu \mathrm{g} / \mathrm{g}$ humic acid), $\mathrm{Ca}(\leq 100 \mu \mathrm{g} / \mathrm{g}$ fulvic acid, $\leq 200 \mu \mathrm{g} / \mathrm{g}$ humic acid), and $\mathrm{Fe}(\leq 20 \mu \mathrm{g} / \mathrm{g}$ fulvic acid, $\leq 400 \mu \mathrm{g} / \mathrm{g}$ humic acid) (Taylor and Garbarino, 1989). The SuwanneeRiver fulvic acid tends to have smaller amounts of metals than the humic acid.

Researchers have used acid-base titrations, proton nuclear magnetic resonance (NMR) and carbon-13 NMR to characterize the acid functionalities of SRDOM. Acid-base titration of the Suwannee River fulvic acid led to an estimate of 6.1 milliequivalents per gram (meq/g) of carboxylic acid functional groups and 1.2 $\mathrm{meq} / \mathrm{g}$ of phenolic acid groups (Bowles et al., 1989). Edwards et al. (1996) 
questioned the ability of the acid-base titration method to distinguish carboxylic groups from phenolic groups. They recommended that NMR be used for the determination of acid functional groups. Noyes and Leenheer (1989) used proton NMR to study the Suwannee River fulvic acid. Their analysis confirmed the titration data to a large extent with an estimate of carboxylic groups at 6.8 $\mathrm{mmol} / \mathrm{g}$ and phenolic groups at $1.4 \mathrm{mmol} / \mathrm{g}$. Carbon-13 NMR analysis supported the distribution of acid functionalities in the fulvic acid as determined by the two other methods (Thorn, 1989). Thorn (1989) reported $6.1 \mathrm{mmol} / \mathrm{g}$ carboxylic acid groups and $1.5 \mathrm{mmol} / \mathrm{g}$ phenolic groups. For the humic acid, Thorn (1989) reported less carboxylic groups $(4.9 \mathrm{mmol} / \mathrm{g})$ and more phenolic groups $(2.9$ $\mathrm{mmol} / \mathrm{g}$ ). The distribution of these particular categories are of interest because they are the functional groups controlling complexation of metals by NOM and sorption of NOM by soils.

\subsubsection{Characterization of CDP}

A few researchers who are studying the mobility of radionuclides and heavy metals have investigated the products derived from the degradation of paper and cardboard waste. Serne et al. (1993) developed several leachates by contacting water and waste materials likely to be co-disposed with defense wastes at the Hanford Site. We will focus on the paper, cardboard, and wood products leachate because it is most similar to ours. Serne et al. (1993) conducted analyses for volatile and semivolatile organic compounds and inorganic compounds including major cations and anions, trace metals as well as $\mathrm{pH}, \mathrm{Eh}$, DOC, and alkalinity. Despite their efforts, less than 4 percent of the total organic carbon was identified as specific compounds over the 12 week period of leaching. No carboxylic acids were isolated and identified. A handful of aromatic alcohols were identified. Low concentrations of cations and anions were observed. At the end of 12 weeks, 9.31 meq/L cations were measured and 9.84 meq/L anions (Serne et al., 1993).

Berry and colleagues (Berry et al., 1991; Baston et al., 1992, 1994a, 1994b) have undertaken a number of studies of the sorption of actinides by selected geosorbents in the presence of CDP and surrogates. They prepared CDP by combining wood, paper, cement, and water and autoclaving the mixture at 80$100^{\circ} \mathrm{C}$ for 30 days under both aerobic and anaerobic conditions (Baston et al., 1994a). They presented limited analysis of the CDP by high performance liquid chromatography. In the CDP prepared anaerobically, they identified isosaccharinate (Figure 3 ) as an important component. They also used gluconate (Figure 3 ) as a simulant because it was readily available and they expected it to be a product of cellulose degradation although they have not isolated it from the CDP that they prepared (Berry et al., 1991; Baston et al., 1994a). Note the presence of carboxylic acid functional groups in both compounds. 
A number of studies have been conducted on the composition of landfill leachates (e.g., Gintautas et al., 1993; Reinhard et al., 1984; Khare and Dondero, 1977). It is unlikely that the array of materials in subtitle $D$ landfills will be found in the disposal of defense wastes, however, it is instructive to consider the generalities observed for landfill leachates. Gintautas et al. (1993) identified a number of carboxylic acids and a few phenols in leachate from subtitle $D$ landfills in Utah, New Jersey, Florida, Wisconsin, Oregon, and Texas. The carboxylic acids included acetic, propanoic, heptanoic, cyclohexane carboxylic, and several benzenedicarboxylic acids. Reinhard et al. (1984) identified several carboxylic acids such as benzoic, phenylacetic, and palmitic acids in two landfills in Ontario, Canada. Khare and Dondero (1977) identified acetic, propanoic, and butyric acids in landfill leachate from New York.

In summary, little work has been undertaken to characterize specifically cellulose degradation products but the work to date indicates that carboxylic acid functional groups will be an important factor.

\subsubsection{Phase / Summary}

Due to the complexities of systems containing CDP, the paucity of site-specific data, and the lack of physicochemical constants (e.g.,nuclide-CDP complexes, CDP sorption to soil surface, and rate of CDP degradation) as a first approximation, we have decided to use chemical surrogates to represent the CDP chemistry in both the previous performance assessment modeling and Phase I of this study.

In the modeling work, simple low-molecular weight organic acids (citrate and EDTA) were used to approximate the chemical behavior of CDP. NOM, like $\mathrm{CDP}$, is a complex mixture of organic compounds. Cellulose degradation processes in forested ecosystems are believed to be a reasonable analogue for cellulose degradation in SRS waste trenches. Therefore, NOM is expected to be more representative of CDP than simple organic acids like citrate or EDTA used in the initial modeling study. In Phase I and II studies, a well-characterized DOC sample isolated from the Suwannee River was chosen as a surrogate for CDP.

\subsection{Materials and Methods - Characterization of CDP}

\subsubsection{Materials}

All solutions were prepared from reagent grade chemicals using DI water in acidwashed, double rinsed glassware, unless otherwise specified. 


\subsubsection{Methods}

\subsubsection{Laboratory Generated CDP}

Actual cellulose degradation products were generated in the laboratory from cellulosic materials known to be present in slit trenches at SRS. Generally, cellulosic solids (paper, cardboard, and wood) were leached with a synthetic rain solution using a procedure similar to that of Serne et al. (1993). The synthetic rainwater was chosen to represent the major ion chemistry in contact with the soil. The synthetic rainwater was prepared by the method of Lee and Weber (1979) $\left(0.6414 \mathrm{mg} / \mathrm{L} \mathrm{NH}_{4} \mathrm{Cl}, 0.7486 \mathrm{mg} / \mathrm{L} \mathrm{CaSO}_{4}, 0.4251 \mathrm{mg} / \mathrm{L} \mathrm{NaNO}_{3}, 0.2022\right.$ $\left.\mathrm{mg} / \mathrm{L} \mathrm{KNO}{ }_{3}, 0.7151 \mathrm{mg} / \mathrm{L} \mathrm{Mg}\left(\mathrm{NO}_{3}\right)_{2} 6 \mathrm{H}_{2} \mathrm{O}\right)$. After equilibration with the atmosphere, the resulting solution $\mathrm{pH}$ was 5.20 .

Two large glass bottles were used to perform a static leaching study. The leaching solution was synthetic rainwater prepared from the recipe of Lee and Weber (1979). Each bottle contained about $800 \mathrm{~g}$ of waste material; $400 \mathrm{~g}$ plywood cut into 1 " $\times 2$ " $\times 3 / 4$ " pieces, $200 \mathrm{~g}$ corrugated cardboard cut into $1^{\text {" }} \times 1$ " pieces, $150 \mathrm{~g}$ brown paper towels cut into $1 \frac{1}{2}{ }^{\prime \prime} \times 2{ }_{2}{ }_{2}$ " pieces, and $50 \mathrm{~g}$ Kimwipes $^{\mathrm{TM}}$. The actual weights of the cellulosic solids used in this study are summarized in Table 1.

\begin{tabular}{|l|r|l|r|}
\hline \multicolumn{3}{|l|}{ Table 1 - CDP Source } \\
\hline Bottle 1 & Bottle 2 \\
\hline Plywood & $401.57 \mathrm{~g}$ & Plywood & $402.02 \mathrm{~g}$ \\
\hline Brown paper towels & $148.46 \mathrm{~g}$ & Brown paper towels & $149.75 \mathrm{~g}$ \\
\hline Corrugated cardboard & $200.53 \mathrm{~g}$ & Corrugated cardboard $^{\text {TM }}$ & $200.04 \mathrm{~g}$ \\
\hline Kimwipes $^{\mathrm{TM}}$ & $49.83 \mathrm{~g}$ & Kimwipes $^{\mathrm{TM}}$ & $49.76 \mathrm{~g}$ \\
\hline Total mass & $800.39 \mathrm{~g}$ & Total mass & $801.57 \mathrm{~g}$ \\
\hline
\end{tabular}

Each bottle also contained $16 \mathrm{~L}$ of synthetic rainwater. The bottles were stored in the dark to simulate subsurface burial, and at a temperature of about $35^{\circ} \mathrm{C}$ to accelerate degradation. A two-hole rubber stopper sealed the top of each bottle, with glass tubing through each hole to allow for sampling. Plastic tubing was connected to the glass tubing with hose clamps, and was sealed from the atmosphere.

During sampling, one of the tubes was compressed with nitrogen gas to prevent exposure to the atmosphere and to facilitate sampling. The other tube was submerged into the leachate to allow for periodic sampling. The tip of this tube 
was covered by a small plastic bottle with many holes punched in the sides to minimize solids for entering the tube. Bottle one was sampled at 1, 3, 6, and 12 weeks and bottle two was sampled at 12 and 19 weeks after the start of the experiment. All samples were filtered through a $0.45 \mu \mathrm{m}$ Acrodisc ${ }^{\mathrm{TM}}$ filter prior to analysis or use in subsequent studies.

\subsubsection{Analytical Measurements}

\subsubsection{1. $\mathrm{pH}$}

All pH measurements were performed using a Corning lon Analyzer model 250 meter and a Corning combination $\mathrm{pH}$ electrode. It was calibrated with $\mathrm{pHydrion}$ Tri-Check buffers.

\subsubsection{Total Organic Carbon}

Total Organic Carbon of each sample containing SRDOM or CDP was measured by ignition using a Shimadzu TOC-5000 total organic carbon analyzer. The use of an ultra-sensitive catalyst in the TOC analyzer necessitated the dilution of all samples by varying factors to avoid overloading the column.

\subsection{Results - Characterization of CDP}

Almost immediately after the waste was placed in the bottle, the water began to turn a brownish-green color. Within one week, the bottles developed a distinctive 'paper mill' odor. A simple water displacement test showed that very little or no gas was being produced in the bottles. Examination of the two 12 week samples and a piece of wood from bottle 1 at week 12 under a light microscope yielded no evidence of microbial activity. A small amount of white mold appeared in the second bottle before its first sampling at week 12.

As expected, the $\mathrm{pH}$ of the CDP slowly decreased with time (Figure 4) from 5.2 at the start to 4.4 at 19 weeks. This is consistent with the production of carboxylic acid and hydroxyl functional groups from degrading wood processes. It is expected that the $\mathrm{pH}$ will continue to drop with time.

After an initial large production of organic carbon in the first week, the TOC of the samples steadily increased from $545 \mathrm{mg} \mathrm{C/L}$ at week 1 , to $1018 \mathrm{mg} \mathrm{C/L}$ at week 19 (Figure 4). The slope of the line TOC data as a function of time (i.e., organic carbon production rate) decreases as the experiment progresses. 


\subsection{Conclusions - Characterization of CDP}

The production of CDP from cellulosic materials known to be present in shallow trench disposal environments is consistent with results expected from studies of the degradation of natural organic matter in terrestrial environments (e.g., leaf litter degradation (Serkiz, 1991)). As was shown in this previous leaf-litter degradation study, there is a significant temporal effect on rate of CDP production with production rates decreasing as a function of increased leaching time. These leaf-litter studies (Serkiz, 1991) have shown that moisture content of the cellulosic source material and the frequency of leaching have a significant influence on the rate of dissolved organic carbon production. Because this characterization study was conducted under static-saturated leaching conditions, the effects of episodic rain events on CDP production and character have not been investigated and are thought to be potentially important.

Also consistent with the behavior of organic matter in terrestrial systems, is a lowering of the aqueous-phase $\mathrm{pH}$ during the cellulosic degradation process. Because the sorption of many nuclides and heavy metals to soil surfaces is very sensitive to small $\mathrm{pH}$ changes in the $\mathrm{pH} 4$ to 7 range, it is thought that the degradation of cellulosic materials could increase the mobility of these contaminants by reducing the $\mathrm{pH}$ of the system near the source of these cellulosic materials. Fortunately, the buffering capacity of the soils will return soils to more neutral $\mathrm{pH}$ values as CDP are transported away from the source and are lost from the system by microbial degradation. It is suggested that some soil column studies with actual CDP addition be conducted to gain further insight into the dynamics of $\mathrm{pH}$ changes from CDP production.

In addition to $\mathrm{pH}$ changes, the major ion chemistry (e.g., $\mathrm{Ca}$ and $\mathrm{Mg}$ ) are also altered by the presence of cellulosic materials. Samples collected from this static-leach test are also being analyzed for major ion concentrations by ICP-ES. Data analysis on these samples, however, has yet to be completed. Once completed, further characterization (e.g., acid-base titration and carbonhydrogen-nitrogen content) of the CDP produced from this study will likely be conducted. These data will then be compared to existing data on the Suwannee River CDP surrogate.

\section{Phase II - CDP Fate}

\subsection{Purpose and Approach - CDP Fate}

The previous hydrogeochemical model (Serkiz and Myers, 1996) has considered sorption of CDP to soil surfaces and mineralization (i.e., degradation) of CDP as mechanisms for CDP loss from the system. The Phase I study examined the sorption of CDP surrogate to SRS soils and kaolinite (a major clay mineral at 
SRS). The purpose of the Phase II study was to (1) examine in laboratory experiments CDP surrogate (i.e., SRDOM) sorption to SRS over a greater range of organic matter concentrations; (2) investigate actual CDP sorption to SRS soils in a series of laboratory experiments; and (3) compile existing data on the mineralization rates of natural organic matter in near-surface systems. These data will subsequently be used to validate and/or update the existing model used to set allowable radionuclide inventories for shallow trench disposal environments in the presence of these cellulosic materials. The experimental data for Items 1 and 2 above were conducted in the presence of added Eu. The experimental conditions $\mathrm{pH}$ range, organic carbon concentration and source, Eu concentration, and order of addition) for these studies are summarized in

Table 2.

Table 2. Experimental Matrix

DOC Concentration Study

\begin{tabular}{|c|c|c|c|}
\hline $\mathbf{p H}$ & {$[$ TOC] $\mathbf{( m g ~ C / L})$} & DOM Source & [Eu] (M) \\
\hline $3-7$ & 500 & SRDOM & $1 \mathrm{E}-06$ \\
\hline $3-10$ & 100 & SRDOM & $1 \mathrm{E}-06$ \\
\hline $3-10$ & 30 & SRDOM & $1 \mathrm{E}-06$ \\
\hline $3-10$ & 10 & SRDOM & $1 \mathrm{E}-06$ \\
\hline $3-10$ & 0 & SRDOM & $1 \mathrm{E}-06$ \\
\hline
\end{tabular}

Eu Concentration Study

\begin{tabular}{|c|c|c|c|}
\hline $\mathbf{p H}$ & [TOC] $\mathbf{( m g}$ C/L) & DOM Source & [Eu] (M) \\
\hline $3-6$ & 10 & SRDOM & $1 \mathrm{E}-06$ \\
\hline $3-6$ & 10 & SRDOM & $5 \mathrm{E}-07$ \\
\hline $3-6$ & 10 & SRDOM & $2.5 \mathrm{E}-07$ \\
\hline $3-6$ & 30 & SRDOM & $1 \mathrm{E}-06$ \\
\hline $3-6$ & 30 & SRDOM & $5 \mathrm{E}-07$ \\
\hline
\end{tabular}

Organic Matter Source and CDP Temporal Study

\begin{tabular}{|c|c|c|c|}
\hline $\mathbf{p H}$ & [TOC] (mg C/L) & DOM Source & [Eu] (M) \\
\hline $3-10$ & 10 & CDP Week 6 & $1 \mathrm{E}-06$ \\
\hline $3-10$ & 30 & CDP Week 6 & $1 \mathrm{E}-06$ \\
\hline $3-10$ & 10 & CDP Week 19 & $1 \mathrm{E}-06$ \\
\hline $3-10$ & 30 & CDP Week 19 & $1 \mathrm{E}-06$ \\
\hline $3-10$ & 10 & SRDOM & $1 \mathrm{E}-06$ \\
\hline $3-10$ & 30 & SRDOM & $1 \mathrm{E}-06$ \\
\hline
\end{tabular}




\subsection{Previous Work - CDP Fate}

\subsubsection{Literature Review}

It is important to understand the fate of CDP entering the soil and groundwater because of its potential for controlling the fate of radionuclides and heavy metals co-disposed with paper, cardboard, and wood materials. Some information about the potential fate of CDP can be gained by examining studies of the fate of native NOM in the southeastern US. Several researchers have observed a decrease in NOM as water containing substantial DOC concentrations moved through soil or aquifer materials (Qualls and Haines, 1991; McCarthy et al., 1993; Dosskey and Bertsch, 1997; Murphy and Schramke, 1998). From their field observations and the work of others in the laboratory (e.g., Tipping, 1981, 1986; Dunnivant et al., 1992; Murphy et al., 1992; Edwards et al., 1996;

Samadfam et al., 1998) several generalizations are possible. Mineral surfaces in soils and aquifer materials are capable of sorbing NOM, in particular iron and aluminum oxides and alumino-silicates. Microorganisms can use NOM as a carbon and energy source. Sorption and biodegradation appear to be the major fate processes for NOM in soils and groundwater with sorption dominating.

\subsubsection{Natural Organic Matter Sorption}

A significant volume of research exists on the sorption of naturally derived organic matter on a variety of mineral phases. Within this body of research, the following physicochemical factors are expected to influence DOC sorption to mineral surfaces:

- Fixed surface charge of solid.

- Compositional variations in solid phase (e.g., functional group density, bond strength, and configuration).

- Reactions at the solid surface that give rise to variations in surface charge (e.g., protonation and deprotonation reactions).

- Character and quantity of organic matter (e.g., polarity and molecular weight).

- Reactions of the organic matter with aqueous species (e.g., protonation/deprotonation and cation complexation reactions).

Several researchers (Sposito, 1984 and Murphy et al., 1990) have postulated a ligand-exchange mechanism for the sorption of naturally occurring DOC to mineral oxide surface. This postulated mechanism is described by the following three reactions:

$$
\mathrm{SOH}+\mathrm{H}^{+} \longleftrightarrow \mathrm{SOH}_{2}^{+}
$$


Where $\mathrm{SOH}$ represents the surface hydroxyl group on the sorbent material.



Where $-\mathrm{O}$ - $\mathrm{C}-\mathrm{DOM}$ represents a carboxyl group on the DOM molecule.<smiles>O=COC(=O)OCCCOC(=O)OCO[Si]</smiles>

For this reaction pathway, the protonation step is thought to make the surface hydroxyl group more reactive (Equation 1), followed by outer-sphere carboxyl group complex formation (Equation 2), and, finally, ligand exchange of $\mathrm{OH}_{2}$ for the carboxyl group resulting in an inner-sphere complex between the carboxyl group and the surface (Equation 3 ).

This reaction pathway is consistent with the general observations of DOC sorption to mineral surfaces. Where the fractional sorption of DOC to mineral surfaces and soils is generally; (1) $\mathrm{pH}$-dependent, with a greater fraction of DOC sorbed at lower $\mathrm{pH}$ values; (2) dependent on total DOC concentration, with a greater fractional sorption at lower DOC concentrations; and (3) variable with respect to the character of both the sorbing surface and the organic matter. The $\mathrm{pH}$-dependent sorption behavior is attributable, at least in part, to the protonation of the surface hydroxyl groups as the initial step in the ligand-exchange reaction pathway. At lower $\mathrm{pH}$ values, the concentration of protonated surface hydroxyl sites is greater, thereby allowing for a larger number ligand exchange reactions to occur. At a constant $\mathrm{pH}$ value the decrease in fractional $\mathrm{DOC}$ sorption with increasing $\mathrm{DOC}$ concentration can be attributed to the lower ratio of protonated hydroxyl surface binding sites to DOC molecules in solution.

Murphy et al., 1990 conducted studies to investigate the influence of organic matter character on DOC sorption to kaolinite and hematite. These mineral phases are also widespread in SRS soils (Johnson, 1995). The Murphy et al. study showed that for a particular organic matter source, fractional DOC sorption on hematite was substantially greater (e.g., approximately 20 percent at a pH of 5) than on kaolinite. This increased sorption on hematite was attributed to a greater surface hydroxyl density for hematite than kaolinite. Furthermore, the character of the organic matter, in particular molecular weight, influenced DOC sorption, where increasing fractional sorption of DOC was correlated with increased molecular weight. Highest fractional sorption and, understandably, highest molecular weights were observed for organic material derived from terrestrial versus aquatic environments. 
Tipping and colleagues (1981a, 1981b, 1982, 1983, 1986) studied the sorption of DOC by a series of iron, manganese, and aluminum oxides and oxyhydroxides in batch studies. They used humic substances isolated from a eutrophic lake in most of the experiments. The extensive studies by Tipping and colleagues resulted in these conclusions: Carboxylic acid groups dominate the properties of the humic substances and interact with metal atoms on the oxide surfaces to form inner sphere complexes through ligand exchange. As $\mathrm{pH}$ increases, sorption of humic substances by the oxides decreases. Other anions such as phosphate may compete with humic substances for the sites on the oxide surfaces. Divalent cations enhance the sorption of humic substances by the oxides.

Rabung et al. (1998) made similar observations for the sorption by hematite of fulvic acid isolated from groundwater and purified Aldrich humic acid. The groundwater fulvic acid had a proton exchange capacity as characterized by titration of $5.70 \mathrm{meq} / \mathrm{g}$ compared to $5.33 \mathrm{meq} / \mathrm{g}$ for the Aldrich humic acid. They observed a decrease in the sorption of $\mathrm{DOC}$ as $\mathrm{pH}$ increased.

Several researchers have investigated the sorption of DOC by kaolinite which is the dominant clay mineral found in the soils of the southeastern coast plain. Murphy et al. (1992) considered the sorption by kaolinite and hematite of Suwannee River humic and fulvic acids as well as two other sources of humic and fulvic acids. They attributed ligand exchange to the observation that sorption of the humic substances increased as the $\mathrm{pH}$ decreased from 7.5 to 4 . In general humic acids were sorbed more strongly than fulvic acids. Murphy et al. (1992) also observed that sorption of humic substances by both kaolinite and hematite increased as the aromaticity of the humic substances increased and the polarity (as measured by the elemental O/C ratio) decreased. The Suwannee humic acid was strongly sorbed by kaolinite and the Suwannee fulvic acid was weakly sorbed in comparison to all the other humic substances considered. For example, at the lowest pH (around 4 ) about 20 percent of the Suwannee fulvic acid was sorbed and about 70 percent of the Suwannee humic acid was sorbed.

Samadfan et al. (1998) reported the sorption of purified Aldrich humic acid by kaolinite. At low pH $(<6)$ more than 85 percent of the Aldrich humic acid was sorbed by the kaolinite. At $\mathrm{pH} 10$ a significantly smaller percentage was sorbed and depended on the initial concentration of humic acid. For a starting concentration of $5 \mathrm{ppm}, 75$ percent or less was sorbed at pH 10; for $10 \mathrm{ppm}, 65$ percent was sorbed; and for $20 \mathrm{ppm}, 37$ percent was sorbed.

Dunnivant et al. (1992) conducted column studies with aquifer materials from the coastal plain near Georgetown, SC, the location of the field study by McCarthy et al. (1993). They ran high concentrations of DOC (55 mg C/L) through the 
columns and observed breakthrough curves. They also fractionated the DOC into hydrophobic acid, hydrophilic acid, and hydrophilic neutral fractions. Dunnivant et al. (1992) observed initial rapid breakthrough of the DOC with lagging concentration increase followed by extended tailing, which predicted the field results observed by McCarthy et al. (1993). The hydrophilic fractions were more rapidly transported through the column than the hydrophobic acid fraction, which indicates that the protonated carboxylic acid groups were preferentially sorbed.

For the type of minerals expected in coastal plain soils sorption of NOM is significant at low $\mathrm{pH}(<6)$. Kaolinite and iron oxides and oxyhydroxides will retain significant quantities of DOC. Laboratory studies found significant removal of DOC from solution by these geosorbents. Field studies confirmed the laboratory work with observations of significant removal of DOC in soils even with low amounts of kaolinite. The consensus is that ligand exchange is the mechanism controlling sorption and that DOC carboxylic acid groups play an important role.

\subsubsection{Field Studies of NOM Fate}

The field studies are particularly pertinent because the work has been conducted in the region of interest. Qualls and Haines (1991) in their work in North Carolina with Ultisol soils found consistent trends with depth in the distribution of the DOC fractions. For example, the hydrophobic acids fraction of the organic matter pool decreased consistently with depth while the hydrophilic acids did not. The percentage of hydrophilic acids fluctuated with depth although overall the percentage in the $\mathrm{C}$ horizon was less than the percentage in the in more shallow horizons. The percentage of hydrophilic neutrals increased with depth although their overall concentration decreased. Qualls and Haines (1991) attributed the removal of hydrophobic acids to sorption by soil minerals. They hypothesized that adsorption by iron and aluminum hydroxides by ligand exchange was responsible for removal of both hydrophobic and hydrophilic acids because both fractions contain carboxylic acid groups. The hydrophilic acid removal may also be related to biodegradation because this fraction contains the small organic acids (Qualls and Haines, 1991). They suggested that the hydrophilic neutrals increased with depth because they are generated by roots and microbes in the soil. They concluded that there is probably more than one mechanism for removal because all fractions decreased in concentration with depth.

Dosskey and Bertsch (1997) found that total DOC decreased with depth in the Ultisols they studied on the coastal plain of South Carolina. Ultisol is the soil order predominantly found in the southeastern US. They are found in warm, humid regions, have low base cation saturation, and are dominated by kaolinite in the clay fraction (Miller and Gardiner, 1998). The mean DOC concentration in 
the A horizon at a depth of $10 \mathrm{~cm}$ was $25.5 \mathrm{mg} \mathrm{C/L}$, in the $\mathrm{E} 1$ horizon at a depth of $30 \mathrm{~cm}$ was $13.7 \mathrm{mg} \mathrm{C/L}$, and in the E2 horizon at a depth from $76-99 \mathrm{~cm}$ was $1.8 \mathrm{mg} \mathrm{C/L}$ (Dosskey and Bertsch, 1997). They concluded that the mineral horizons of the Ultisol retained substantial amounts of DOC which contradicted their expectation. They hypothesized that low clay content and lack of spodic development, which occurs with the accumulation of organic matter and $\mathrm{Fe}$ and Al minerals in the B horizon, would lead to transport of DOC through the soil. They attribute the retention of DOC to kaolinite and Fe oxides. Dosskey and Bertsch (1997) speculated that sorptive capacity of the limited clay surfaces is maximized by rapid microbial degradation. However, they do not provide any evidence for biodegradation of DOC at their field site.

The field study by McCarthy et al. (1993) followed the fate of DOC that was injected into a sandy, coastal plain aquifer in SC. High concentrations of DOC $(66 \mathrm{mg} \mathrm{C/L})$ were injected over 312 hours and monitored at multilevel samplers at $1.5,3$, and $5 \mathrm{~m}$ downgradient of the injection point. Water with low levels of DOC was injected for another 2,688 hours and was monitored at the same locations. The breakthrough of injected DOC was retarded in comparison to the chloride tracer and exhibited considerable tailing after injection of the high DOC water was stopped. Fractionation of the injected DOC and the DOC withdrawn from the monitoring and production wells indicated that the hydrophobic acid fraction was retained to a greater degree than the hydrophilic acid and the hydrophilic neutral fractions. McCarthy et al. (1993) concluded that their results indicated sorption of the DOC by the aquifer materials. They suggested that the kinetics of sorption required a certain contact time based on evidence from the breakthrough curves for DOC and chloride at the various monitoring wells. They also found no evidence for microbial degradation of the DOC during the 3000 hour experiment. They concluded that the observed transport behavior of DOC was due to sorption and desorption processes. McCarthy et al. (1993) also concluded that their experiment indicated that metals and radionuclides are likely to be mobilized by the hydrophilic fractions that were not retained to the extent that the hydrophobic fraction was. However, these conclusions depend on consistently high concentrations of DOC being injected over a relatively long period of time until steady state is reached, sorption sites are filled to capacity, and the injected concentrations of DOC equal the withdrawn concentrations.

\subsubsection{Natural Organic Matter Mineralization}

Little work has been conducted on the microbial degradation of DOC in groundwater. Murphy and Schramke (1998) studied the microbial respiration rates in the Middendorf aquifer of the coastal plain of SC. The Middendorf aquifer is a deep aquifer system that has been extensively studied in terms of its geochemistry and mineralogy. The flowpath that Murphy and Schramke (1998) 
sampled and modeled required about 14,000 years travel time based on carbon14 dating. Based on the five wells along the flowpath that were sampled, they found that little oxidation of organic carbon occurs beyond a groundwater age of about 6,000 years. They conclude that the respiration rates indicated that the majority of carbon oxidation occurs early in the flow path where there is a transition zone between oxic and anoxic groundwater and the terminal electron acceptors and the microbial communities are diverse. The respiration rates they determined are in line with other rates determined in similar groundwater environments and two to five orders of magnitude less than respiration rates measured for river and lake freshwater sediments. Therefore, even the highest rates measured by Murphy and Schramke (1998) are much lower than surface water rates for biodegradation of organic carbon.

From the field studies, there is evidence that DOC is retained by Ultisol soils with low clay content and that there is degradation of the DOC by microorganisms, however, degradation occurs at much slower rates in groundwater than in surface water. Laboratory studies of sorption of DOC by geosorbents confirm that sorption is significant.

\subsubsection{Phase I Summary}

The results of Phase I experiments from our work and much previous research show that sorption of natural $\mathrm{OM}$ varies as a function of $\mathrm{pH}$ and total carbon content, with fractional sorption increasing with decreasing organic carbon content and decreasing $\mathrm{pH}$. Over the range of experimental conditions examined in the Phase I study (pH 3 to 8 and NOM concentration from 10 to 500 $\mathrm{mg} \mathrm{C/L)} \mathrm{fractional} \mathrm{sorption} \mathrm{of} \mathrm{organic} \mathrm{matter} \mathrm{varied} \mathrm{from} \mathrm{several} \mathrm{percent} \mathrm{to} \mathrm{about}$ 60 percent.

\subsection{Materials and Methods - CDP Fate}

\subsubsection{Materials}

All solutions were prepared from reagent grade chemicals using DI water in acidwashed, double rinsed glassware, unless otherwise specified.

\subsubsection{CDP Surrogate Organic Matter}

The isolated natural organic matter (NOM) used in this study was collected from the Suwannee River and has been characterized extensively (Serkiz and Perdue, 1991). This NOM is a complex mixture of organic compounds, and is believed to resemble more closely the products from the degradation of cellulosic material than any single organic compound. 
Suwannee River NOM is a complex mixture of humic substances (fulvic acid and humic acid), hydrophilic acid, and simple compounds (carbohydrates, carboxylic acids, amino acids, and hydrocarbons). Humic and fulvic substances account for 24 and 37 percent respectively of the dissolved organic carbon present in the NOM used in this study (Serkiz and Perdue, 1991).

A stock solution of NOM at a final concentration of approximately $3500 \mathrm{mg} \mathrm{C/L}$ was prepared by dissolving $714.3 \mathrm{mg}$ of lyophilized SRDOM isolate in $100 \mathrm{ml}$ of DI water.

\subsubsection{Laboratory Generated CDP}

Actual CDP was generated in a set of static-leaching tests as described above in Section 4.3.2.1. Enough of this material collected at 6 or 19 weeks was added to make a final concentration of 10 and $30 \mathrm{mg} \mathrm{C/L}$.

\subsubsection{SRS Soil}

The soil used for this study, identified as GC5, was collected from the "Little Grand Canyon" located in the F Area of SRS. Lithologically, this sample is identical to the surface soils in the Burial Ground Complex. Previous sorption studies of uranyl and cadmium have been conducted on this sample and, as part of these studies, the soil was well characterized by Johnson (1995) and Johnson (1994). Soil texture was characterized as 96.1 percent sand, 0.0 percent silt, and 3.8 percent clay. The dominant minerals in the clay-size fraction were kaolinite and to a lesser extent, illite. The measured cation exchange capacity (CEC) was $3.9 \mathrm{meq} / \mathrm{kg}$ and the soil $\mathrm{pH}$ in water was 4.78 . Although carbon content of this particular sample was not measured, all other samples they collected had a carbon content of less than 0.05 percent. Details of the soil characterization can be found in Johnson (1994) and Johnson (1995). The organic carbon content of the soil was measured as 0.04 percent carbon by ignition in this study.

\subsubsection{Solution Chemistry}

To simulate leaching of contaminants from the disposal area, synthetic rainwater was chosen as the major ion chemistry in contact with the soil. The synthetic rainwater was prepared by the method of Lee and Weber (1979) $(0.6414 \mathrm{mg} / \mathrm{L}$ $\mathrm{NH}_{4} \mathrm{Cl}, 0.7486 \mathrm{mg} / \mathrm{L} \mathrm{CaSO}_{4}, 0.4251 \mathrm{mg} / \mathrm{L} \mathrm{NaNO}_{3}, 0.2022 \mathrm{mg} / \mathrm{L} \mathrm{KNO}_{3}$, $\left.0.7151 \mathrm{mg} / \mathrm{L} \mathrm{Mg}\left(\mathrm{NO}_{3}\right)_{2} \cdot 6 \mathrm{H}_{2} \mathrm{O}\right)$. After equilibration with the atmosphere, the resulting solution $\mathrm{pH}$ was 5.20 . 


\subsubsection{Methods}

\subsubsection{Batch Sorption Experiments}

A series of batch sorption experiments of DOC (both SRDOM and laboratory generated $\mathrm{CDP}$ ) to SRS soils were conducted under the $\mathrm{pH}$ range, total added Eu, total added DOC, and NOM source described in Table 2.

More specifically, a $0.833-\mathrm{g}$ sample of GC5 soil was added to each $42-\mathrm{ml}$ polyallomer Oak Ridge centrifuge tube. To this, $20 \mathrm{ml}$ of synthetic rainwater was added, and the tubes were placed on a linear shaker for one hour to create a soil suspension. The sorption experiments were initiated by adding the appropriate amount of $10 \mathrm{ppm}$ Eu stock and NOM stock solution. Synthetic rainwater was then added to a final solution volume of $35 \mathrm{ml}$ and the $\mathrm{pH}$ of each tube was then adjusted with standardized $\mathrm{HNO}_{3}$ or $\mathrm{NaOH}$. Soil suspensions were then returned to the shaker for overnight equilibration. After equilibration, the supernatant was separated by centrifugation for $13 \mathrm{~min}$ at $16,000 \mathrm{~g}$, followed by filtration through $0.45-\mu \mathrm{m}$ membrane filters. The final equilibrium $\mathrm{pH}$ of the filtrate was measured. After $\mathrm{pH}$ measurement, each sample was preserved with ultrapure $\mathrm{HNO}_{3}$ prior to Eu analysis.

\subsubsection{Analytical Measurements}

\subsubsection{1. pH}

All pH measurements were performed using a Corning lon Analyzer model 250 meter and a Corning combination $\mathrm{pH}$ electrode. It was calibrated with pHydrion Tri-Check buffers.

\subsubsection{Total Organic Carbon}

Total Organic Carbon of each sample containing SRDOM or CDP was measured by ignition using a Shimadzu TOC-5000 total organic carbon analyzer. The use of an ultra-sensitive catalyst in the machine necessitated the dilution of all samples by varying factors to avoid overloading the column.

\subsection{Results - CDP Fate}

The fate of natural organic matter such as cellulose degradation products in the subsurface depends on the degree to which it is retained by the soil. This is determined by the sorption characteristics of the organic matter on that particular soil. An investigation of the sorption behavior of different types of organic matter gives insight into its fate in the environment. 


\subsubsection{Suwannee River Organic Matter}

The sorption behavior of SRDOM to SRS soil was found to vary with $\mathrm{pH}$ at low concentrations of $10 \mathrm{mg} \mathrm{C/L}$ (see Figure $5 \mathrm{a}$ ). At a pH of approximately 2.8 , fractional sorption is around 75 percent, but begins to drop quickly around $\mathrm{pH}$ 5.5. Sorption decreases to 50 percent at a $\mathrm{pH}$ of 8.5 , and falls to 30 percent at $\mathrm{pH} 11$.

At a slightly higher DOC concentration of $30 \mathrm{mg} \mathrm{C/L}$, the strong $\mathrm{pH}$ dependence of the fractional sorption is not observed (see Figure $5 \mathrm{~b}$ ). Fractional sorption is significantly lower, and remains relatively constant at around 25 percent. There appears to be a relatively weak $\mathrm{pH}$-dependence in these data with a slight reduction in fractional sorption at higher $\mathrm{pH}$ values.

At significantly higher DOC concentrations $(100,500 \mathrm{mg} \mathrm{C/L}$ (Figures $5 \mathrm{c}$ and $5 d$ ), a weak pH dependence is also seen. In the case of $100 \mathrm{mg} \mathrm{C/L}$, sorption is at a maximum of about 30 percent at low $\mathrm{pH}$, and decreases slightly to 25 percent at $\mathrm{pH} 10$. At $500 \mathrm{mg} \mathrm{C} / \mathrm{L}$, the maximum sorption of 20 percent also occurs at low $\mathrm{pH}$, and decreases to just 5 percent by $\mathrm{pH} 6$.

\subsubsection{Laboratory Generated CDP}

In order to investigate the temporal affects of CDP generation on its sorption to SRS soil, laboratory-generated CDP samples were used as the organic matter source in the batch sorption studies across a pH range of 3-10. Week 6 and week 19 samples were chosen to observe aging effects of CDP. Additionally, the effects of CDP concentration were investigated by using both CDP samples at 10 and $30 \mathrm{mg} \mathrm{C/L}$.

In all cases, $\mathrm{pH}$ had little effect on the fractional sorption of the CDP to SRS soil (Figure 6). The sorption of Suwannee River CDP surrogate showed a much greater $\mathrm{pH}$ dependence than the laboratory-generated CDP (Figure 5).

Consistent with a large body of data for NOM sorption to geomedia including SRS soils, laboratory-generated CDP shows a decreased fraction sorbed with increasing $\mathrm{pH}$. This effect, however, was much less pronounced for the CDP than for the SRDOM.

For laboratory-generated CDP at $10 \mathrm{mg} C / \mathrm{L}$ sorption decreased slightly with increasing $\mathrm{pH}$ (Figures $6 \mathrm{a}$ and $6 \mathrm{~b}$ ) with a fractional sorption of 80 percent at $\mathrm{pH} 3$ and 70 percent at $\mathrm{pH} 10$. At $30 \mathrm{mg} \mathrm{C} / \mathrm{L}, \mathrm{CDP}$ sorption was not significantly 
affected by $\mathrm{pH}$ (Figures $6 \mathrm{c}$ and $6 \mathrm{~d}$ ) with a fractional sorption of around 20 percent. As was observed with the SRDOM, CDP concentration had a large effect on the fractional sorption of DOC. At $10 \mathrm{mg} \mathrm{C/L,75-80} \mathrm{percent} \mathrm{of} \mathrm{the}$ organic carbon was sorbed to the soil, while at $30 \mathrm{mg} \mathrm{C/L}$, only about $15-25$ percent of the organic carbon was removed from solution by sorption to the soil.

The age of the CDP also had little influence on its sorption to SRS soils (Figure $6 a$ and $6 \mathrm{~b}(10 \mathrm{mg} \mathrm{C/L})$ and Figures $6 \mathrm{c}$ and $6 \mathrm{~d}(30 \mathrm{mg} \mathrm{C/L})$ ). At similar concentrations, both week 6 and week 19 CDP had similar fractional sorption over the entire $\mathrm{pH}$ range.

\subsection{Conclusions - CDP Fate}

Sorption of the SRDOM (CDP surrogate) to SRS soils is somewhat dependent on the system $\mathrm{pH}$ and highly dependent on the total concentration of organic matter. With lower $\mathrm{pH}$ and lower total organic carbon content favoring increased fractional sorption.

At disposal trench $\mathrm{pH}$ values and low organic carbon content, SRDOM was generally an acceptable surrogate for actual CDP sorption to SRS soils. At low$\mathrm{pH}$ values and low organic carbon content, the sorption of both the CDP and SRDOM are similar. This is fortuitous, as this is in the range of $\mathrm{pH}$ values expected in SRS trench disposal environments, but the comparison could not be directly extended to higher $\mathrm{pH}$ regimes. At high $\mathrm{pH}$ values, sorption of laboratory generated CDP to SRS soils did not exhibit a large $\mathrm{pH}$ dependence. This suggests that the $\mathrm{OM}$ quality (e.g., acid-base chemistry and molecular weight) of these two materials is substantially different.

At $10 \mathrm{mg} \mathrm{C/L}$, both the surrogate and the CDP have a fractional sorption of around 80 percent in the $\mathrm{pH}$ range of interest for the conditions at SRS (3-6). Above this $\mathrm{pH}$, both show a decrease in sorption with increasing $\mathrm{pH}$. At an organic matter concentration of $30 \mathrm{mg} \mathrm{C} / \mathrm{L}$, the fractional sorption decreases to around 20 percent and is not significantly affected by changes in $\mathrm{pH}$. The DOC concentration effects were similar for both surrogate and CDP. The influence of DOC concentration at higher values was not included in the experimental matrix for laboratory generated CDP and cannot, therefore, be evaluated.

There were little temporal effects of CDP sorption to SRS soils within the timeframe of these experiments 6 to 19 weeks. 
Little work has been conducted on the microbial degradation of DOC in groundwater. From the field studies, there is evidence that DOC is retained by Ultisol soils with low clay content and that there is degradation of the DOC by microorganisms, however, degradation occurs at much slower rates in groundwater than in surface water (Dosskey and Bertsch, 1997). It was speculated that sorptive capacity of the limited clay surfaces is maximized by rapid microbial degradation resulting in this rapid organic matter loss. If this is true, the production of carbon dioxide could result in elevated levels of aqueousphase carbonate that, in turn, could lead to increased actinide mobility by the formation of carbonate complexes in solution.

Laboratory studies of sorption of DOC by geosorbents confirm that sorption is significant. This is consistent with field studies in soils from coastal plain of South Carolina that showed mean organic matter concentrations decreasing rapidly with depth.

\section{Phase II - Radionuclide Partitioning Studies}

\subsection{Purpose and Approach - Radionuclide Partitioning Studies}

The previous literature review, modeling exercise, and experimental studies have identified a number of factors thought to control nuclide sorption in the presence of cellulosic materials. These included: $\mathrm{pH}$, natural organic carbon content, and nuclide of interest. Furthermore, the conceptual hydrogeochemical model has been developed on the premise that the overall system behavior (i.e., the soilCDP-metal/nuclide ternary system) can be described as the sum of the contributions of each of the binary systems (soil-metal/nuclide, soil-CDP, CDPmetal/nuclide). Data generated in the radionuclide partitioning study are designed to provide the basis to evaluate this conceptual approach. In particular, the sorption of the trivalent lanthanide $\mathrm{Eu}^{3+}$ and the divalent actinide $\mathrm{UO}_{2}{ }^{2+}$ to SRS soils or clays prevalent at SRS in the presence of this CDP surrogate was examined in a series of laboratory experiments. These multivalent cations were chosen for further study because previous modeling of this system (Serkiz and Myers, 1996) predicted that CDP would have the greatest influence on their mobility.

The influences of $\mathrm{pH}, \mathrm{DOC}$ concentration, Eu concentration, NOM source, and temporal effects of CDP generation on Eu sorption to SRS soil were studied. For all organic matter and Eu concentrations, the experiments covered a minimum $\mathrm{pH}$ range of 3 to 6 . Organic matter concentrations investigated were $0,10,30$, 100 , and $500 \mathrm{mg} \mathrm{C/L}$ for the Suwannee River CDP surrogate (with the 0 and 500 $\mathrm{mg} \mathrm{C/L}$ results having already been presented in the Phase I report (Serkiz et al. (1998)) and 10 and $30 \mathrm{mg} \mathrm{C/L}$ for the laboratory-generated CDP at a total added Eu concentration of $10^{-6} \mathrm{M}$. 
Eu concentration effects were evaluated at levels of $10^{-7} \mathrm{M}, 2.5 \times 10^{-7} \mathrm{M}, 5.0 \times 10^{-7}$ $\mathrm{M}$, and $10^{-6} \mathrm{M}$ added Eu at an DOC concentration of $10 \mathrm{mg} \mathrm{C/L}$.

The influences of organic matter source and temporal changes in CDP character on Eu sorption were evaluated by comparison of ternary system experiments with Suwannee River CDP surrogate or laboratory-generated CDP from week 6 and 19 at 10 and $30 \mathrm{mg} \mathrm{C/L}$. The experimental conditions for these tests is summarized in Table 2.

A kinetic study to confirm the overnight equilibration time for Eu sorption to SRS soil was completed using a Eu concentration of $10^{-6} \mathrm{M}$ at a pH of 5-5.5 to evaluate if sorption equilibrium was achieved under the experimental conditions used in this study. The test was run for a maximum equilibration time of 96 hours.

\subsection{Previous Work - Radionuclide Partitioning Studies}

\subsubsection{Literature Review}

Previous work has been conducted on the sorption of $U$ (Johnson, 1995) and Eu (Clark et al., 1998) to GSA soils in the absence of organic matter. Both studies showed very similar sorption behavior. Typical of these systems, sorption behavior is nonlinear with respect to solution $\mathrm{pH}$. At $\mathrm{pH}$ values below 4 the majority of the nuclide remains in solution phase. In the $\mathrm{pH}$ range between 4 and 6 the fractional sorption of the metal increases rapidly to near 100 percent where it remains to a $\mathrm{pH}$ of 7 (highest $\mathrm{pH}$ value investigated in these studies).

There has also been work specifically designed to study cellulose degradation products and their influence on radionuclide transport. Baston et al. (1992) investigated the effects of organic degradation products and gluconate on the sorption behavior of uranium (IV and VI), thorium (IV), and plutonium (IV) to certain geologic materials. They produced their own CDP from a mixture of tissue, cement, and water, and rationalized the use of gluconate as a CDP surrogate to simplify the system. Gluconate is a readily available polyhydroxycarboxylic acid that has functional groups similar to those of CDP. The results of the Baston et al. (1992) study showed differing effects of actual CDP and gluconate on radionuclide sorption behavior. In all cases, gluconate had a greater effect on lowering the amount of radionuclide sorbed to the soil than actual cellulose degradation products.

A later study by Baston et al. (1994) extended the work described above to include the investigation of iso-saccharinate, in addition to gluconate, as a CDP surrogate. Analysis of degradation solution products formed by anaerobic processes using HPLC showed iso-saccharinate as an important constituent, as 
opposed to the aerobic solution that did not contain significant amounts of the compound. Their experiments examined the effects of the two surrogates and actual CDP concentrations at $\mathrm{pH}$ values of 8 and 12 on $\mathrm{Pu}$ and Th sorption to several geologic materials. In the case of $\mathrm{Pu}$ at $\mathrm{pH} 8$, increasing gluconate concentration decreased sorption to a significant extent and increasing isosaccharinate concentration decreased sorption. Only the degradation products generated under aerobic conditions showed a significant decrease in sorption for $\mathrm{Pu}$ at $\mathrm{pH}$ 8. At pH 12, gluconate enhanced sorption to varying degrees, while iso-saccharinate decreased sorption for one soil type and enhanced sorption for the other. The anaerobic degradation products again decreased sorption, while the aerobic products did not. In the case of thorium, the trends were not as apparent. At a pH of 8, gluconate enhanced sorption up to the highest concentration, where the degree of sorption decreased. The aerobic degradation products only affected one soil type, increasing sorption when diluted, and decreasing sorption when used at full strength. At pH 12, increasing gluconate concentration only affected sorption in one soil type, resulting in decreased sorption. A similar effect was seen with the actual degradation products.

The work of Serne et al. (1993) also investigated the sorption of certain radionuclide ions to Hanford sediments in the presence of their degradation products. Of all the ions studied, they found that only $\mathrm{Co}^{2+}, \mathrm{Sr}^{2+}$, and $\mathrm{UO}_{2}{ }^{2+}$ sorption were affected by the presence of cellulose degradation products and $\mathrm{TcO}_{4}^{-}, \mathrm{I}, \mathrm{CrO}_{4}{ }^{2-}, \mathrm{SeO}_{4}{ }^{2-}, \mathrm{Cs}^{+}$, and $\mathrm{NpO}_{2}{ }^{+}$were unaffected.

\subsubsection{Phase I Summary}

The Phase I study showed the nonlinear sorption behavior of uranyl and Eu (III) as a function of $\mathrm{pH}$ in the absence of organic matter. At higher $\mathrm{pH}$ values, where the fractional sorption of the metal approaches 100 percent and exhibits only small changes in sorption behavior in response to $\mathrm{pH}$, a concentration based $\mathrm{K}_{\mathrm{d}}$ approach appears to provide a good fit to the experimental data. For uranyl sorption, at $\mathrm{pH}$ values near the $\mathrm{pH}_{50}$ (the $\mathrm{pH}$ where 50 percent of the metal is sorbed) which for uranyl is about 4.5 , large changes in sorption behavior are expected to occur with small changes in $\mathrm{pH}$. Cellulose will degrade to form natural organic acids and these materials are capable of reducing the $\mathrm{pH}$ of the system. The $\mathrm{pH}$ reduction caused by the generation of these organic acids could, therefore, significantly alter the fractional sorption of the nuclide of interest as well as the major ion chemistry of the system.

Phase I experiments and much previous research show that sorption of natural $\mathrm{DOC}$ varies as a function of $\mathrm{pH}$ and total carbon content. Sorption increases with decreasing organic carbon content and decreasing $\mathrm{pH}$. Over the range of experimental conditions examined in this study $(\mathrm{pH} 3$ to 8 and DOC 
concentration from 10 to $500 \mathrm{mg} \mathrm{C/L}$ ) fractional sorption of organic matter varied from several percent to about 60 percent.

In the presence of naturally occurring organic matter, a significant effect of $\mathrm{pH}$ and organic matter concentration was observed for $U$ and Eu sorption. Over the range of experimental conditions examined in this study the following summarizes the influence of CDM surrogate on $U$ and Eu sorption (i.e., decreased mobility):

\section{Low Organic High Organic}

Low pH $\quad \Uparrow$ sorption $\quad \Uparrow$ sorption

High pH $\quad$ no effect $\quad \Downarrow$ sorption

Specifically, for uranyl at $\mathrm{pH}$ values below 4.5 the effect was to increase the fractional sorption (reduce mobility) of uranyl when compared to experiments without the $\mathrm{DOC}$ and at $\mathrm{pH}$ values above 4.5 , the effects of DOC on the fractional sorption of uranyl were dependent on the concentration of added DOC. At the low DOC concentration ( $10 \mathrm{mg} \mathrm{C/L}$ ), fractional sorption of uranyl was enhanced over the entire $\mathrm{pH}$ range relative to the high $\mathrm{DOC}$ experiments. At the higher $\mathrm{DOC}$ concentration $(30 \mathrm{mg} \mathrm{C/L})$ and $\mathrm{pH}$ values above 4.5 , uranyl sorption was suppressed between 40 and 50 percent. As the fractional sorption of NOM decreases with increasing NOM concentration, the reduced uranyl sorption in this system could be explained by increased aqueous complexation of uranyl ions by NOM. For Eu sorption in the presence naturally occurring OM, as was the case for uranyl at the high NOM concentration, enhanced sorption occurred at the very lowest $\mathrm{pH}$ values (c. $\mathrm{pH}$ of 3 ) and was suppressed by about 50 percent at higher $\mathrm{pH}$ values.

\subsection{Materials and Methods - Radionuclide Partitioning Studies}

\subsubsection{Materials}

All solutions were prepared from reagent grade chemicals using DI water in acidwashed, double rinsed glassware, unless otherwise specified.

\subsubsection{CDP Surrogate Organic Matter}

The isolated natural organic matter (NOM) used in this study was collected from the Suwannee River and added from a stock solution as described in Section 5.3.1.1 of this report. 


\subsubsection{Laboratory Generated CDP}

Actual CDP were generated in the laboratory as described above in section 4.3.2.1.

\subsubsection{SRS Soil}

The soil used in this study was collected from SRS and is described in Section 5.3.1.3 of this report.

\subsubsection{Solution Chemistry}

The simulated rainwater recipe of Lee and Weber (1979) as described in Section 5.3.1.4 was used as the bulk aqueous chemistry for the batch sorption experiments.

A $10,000 \mathrm{ppm} \mathrm{Eu}{ }^{3+}$ standard in 5 percent $\mathrm{HNO}_{3}$ was obtained from Spex Centriprep (lot \# HS-94Eu). A stock solution in 1 percent $\mathrm{HNO}_{3}$ was prepared at a concentration of $10 \mathrm{ppm} \mathrm{Eu}$, which was used to spike each sample. From this stock, calibration standards also in 1 percent $\mathrm{HNO}_{3}$ were prepared at concentrations of $1,10,25,50,75,100$, and $150 \mathrm{ppb}$.

\subsubsection{Methods}

\subsubsection{Batch Sorption Experiments}

A series of batch sorption experiments evaluating sorption of Eu to SRS soils were conducted under the $\mathrm{pH}$ range, total added $\mathrm{Eu}$, total added $\mathrm{DOC}$, and NOM source summarized in Table 2. The batch sorption experiments were conducted as described in Section 5.3.2.1 of this report.

\subsubsection{Analytical Measurements}

\subsubsection{Eu Analysis}

Europium concentrations in the solution phase were determined by graphite furnace AAS (Perkin Elmer 5100: HGA-600 furnace with Zeeman background correction). Furnace conditions were those recommended by the manufacturer. Measurements were made in duplicate or triplicate. 


\subsubsection{2.pH}

All pH measurements were performed using a Corning lon Analyzer model 250 meter and a Corning combination $\mathrm{pH}$ electrode. It was calibrated with pHydrion Tri-Check buffers.

\subsubsection{Total Organic Carbon}

Total Organic Carbon of each sample containing SRDOM or CDP was measured by ignition using a Shimadzu TOC- 5000 total organic carbon analyzer. The use of an ultra-sensitive catalyst in the machine necessitated the dilution of all samples by varying factors to avoid overloading the column.

\subsection{Results - Radionuclide Partitioning Studies}

The concentration of organic matter in the batch system significantly affects the sorption of Eu to SRS soil. This section describes the sorption of Eu to SRS soils in the absence of organic matter and in the presence of organic matter, both NOM and CDP, at varying organic matter concentration.

\subsubsection{Organic Matter Concentration}

With no organic matter present, the fractional sorption of Eu increases sharply from 40 percent at $\mathrm{pH} 3$ to 100 percent at $\mathrm{pH} 4.5$ where it remains until a $\mathrm{pH}$ of 8 , above which some scattering of the data occurs (Figure 7). This $\mathrm{pH}$ functionality on cation sorption is the classic behavior for cation sorption to metal hydroxide surfaces and can largely be explained by the electrostatic interactions between the cation in solution and a sorption surface that has a pH-dependant surface charge. Therefore, at low-pH values the surface is protonated and is more repulsive to the cation in solution. Conversely, at high-pH values the surface becomes more negatively charged and, therefore, more electrostatically attractive to a cation in the aqueous phase. The reason for this scattering at high $\mathrm{pH}$-values is not completely understood. The scatter could be from the variable incorporation of $\mathrm{CO}_{2}$ gas from the atmosphere during the experiment. Because carbonate is most soluble at higher $\mathrm{pH}$ values, this effect should occur only at higher $\mathrm{pH}$ values where the formation of Eu-carbonate complexes are predominant. Because Eu and carbonate form a strong bond, small variations in the incorporation of $\mathrm{CO}_{2}$ gas from the atmosphere are expected to result in large changes in Eu sorption.

The influence of CDP surrogate Suwannee River NOM on Eu sorption to SRS soil was investigated at NOM concentrations of $10,30,100$, and $500 \mathrm{mg} \mathrm{C/L}$ (Figure 8). At $10 \mathrm{mg}$ C/L NOM (Figure 8a), sorption is similar to the no added 
organic matter experiments (Figure 7) with 40 percent at $\mathrm{pH} 3$, and rises sharply to 100 percent at $\mathrm{pH} 4.5$. At higher $\mathrm{pH}$ values, however, sorption begins to decrease above $\mathrm{pH} 5.5$ to a value of 70 percent at $\mathrm{pH} 9.5$. At $30 \mathrm{mg}$ C/L NOM (Figure $8 \mathrm{~b}$ ), sorption is again 40 percent at $\mathrm{pH} 3$ and increases sharply above this $\mathrm{pH}$, but to a maximum sorption of only 90 percent at $\mathrm{pH} 4.5$. As in the $10 \mathrm{mg}$ $\mathrm{C} / \mathrm{L}$ data, sorption for the $30 \mathrm{mg} \mathrm{C/L}$ system begins to decrease around $\mathrm{pH} 5.5$ to a value of about 65 percent at $\mathrm{pH} 7.5$. Increasing the organic matter concentration to $100 \mathrm{mg} \mathrm{C/L}$ significantly changes the shape of the Eu sorption (Figure 8c). At a pH of 3,70 percent of the added Eu sorbs to the solid phase. As the $\mathrm{pH}$ increases, the sorption steadily decreases to a minimum of 50 percent at $\mathrm{pH}$ 7. At an NOM concentration of $500 \mathrm{mg} \mathrm{C/L}$ (Figure 8d) the shape of the sorption is similar to the shape of the $100 \mathrm{mg} \mathrm{C/L}$ sorption. The sorption reaches a maximum of about 50 percent at $\mathrm{pH} 3$ and decreases above that $\mathrm{pH}$ to around 40 percent at $\mathrm{pH} 6$. No data were collected above a $\mathrm{pH}$ of 6 .

In contrast to the Suwannee River NOM where a systematic reduction in sorption was observed at higher $\mathrm{pH}$ values with increasing organic matter concentration, no influence of laboratory-generated CDP concentration was observed for the 10 and $30 \mathrm{mg} \mathrm{C/L}$ systems investigated (see Figures $9 \mathrm{a}$ and $9 \mathrm{c}$ and Figures $9 \mathrm{~b}$ and 9d). This finding was consistent for both CDP collected after 6 and 19 weeks of static leaching.

\subsubsection{Eu Concentration}

Eu concentration effects were evaluated at $10^{-7} \mathrm{M}, 2.5 \times 10^{-7} \mathrm{M}, 5.0 \times 10^{-7} \mathrm{M}$, and $10^{-6} \mathrm{M}$ added Eu at an DOC concentrations of 10 and $30 \mathrm{mg} \mathrm{C/L}$. Over this range of added $\mathrm{Eu}$, the total added the equilibrium solid-phase concentration is relatively linearly related to the aqueous concentration (i.e., linear isotherm) at each $\mathrm{pH}$ value (Figure 10). The equilibrium $\mathrm{pH}$, however, has a pronounced effect on the slope of the sorption isotherm.

\subsubsection{Organic Matter Source}

The influence of organic matter source (either Suwannee River NOM used as a surrogate for CDP or actual laboratory-generated CDP) was evaluated by a series of batch experiments conducted at $10^{-6} \mathrm{M}$ added Eu and organic contents of 10 and $30 \mathrm{mg} \mathrm{C/L}$. These results are summarized in Figure 11.

In the presence of $10 \mathrm{mg} \mathrm{C/L}$ of week $6 \mathrm{CDP}$, the sorption edge rises sharply from 30 percent at $\mathrm{pH} 3$ to a maximum of 100 percent at $\mathrm{pH} 5$. Sorption remains at about 100 percent up to $\mathrm{pH} 10$. Increasing the week 6 CDP concentration to $30 \mathrm{mg} \mathrm{C/L}$ does not significantly affect the Eu sorption. Very similar Eu sorption behavior is observed for week 19 CDP. 
At $10 \mathrm{mg} \mathrm{C/L} \mathrm{SRDOM,} \mathrm{sorption} \mathrm{is} \mathrm{similar} \mathrm{to} \mathrm{the} \mathrm{no} \mathrm{added} \mathrm{organic} \mathrm{matter}$ experiments with 40 percent at $\mathrm{pH} 3$, and rises sharply to 100 percent at $\mathrm{pH} 4.5$. At higher $\mathrm{pH}$ values, however, sorption begins to decrease above $\mathrm{pH} 5.5$ to a value of 70 percent at $\mathrm{pH} 9.5$. At $30 \mathrm{mg} \mathrm{C/L} \mathrm{SRDOM,} \mathrm{sorption} \mathrm{is} \mathrm{again} 40$ percent at $\mathrm{pH} 3$ and increases sharply above this $\mathrm{pH}$, but to a maximum sorption of only 90 percent at $\mathrm{pH} 4.5$. As in the $10 \mathrm{mg} \mathrm{C/L}$ data, sorption for the $30 \mathrm{mg}$ $\mathrm{C} / \mathrm{L}$ system begins to decrease around $\mathrm{pH} 5.5$ to a value of about 65 percent at $\mathrm{pH} 7.5$.

The primary differences between the influence of laboratory-generated CDP and SRDOM on Eu sorption were that; (1) the $\mathrm{pH}_{50 \%}$ for CDP may be slightly (approximately $0.2 \mathrm{pH}$ units higher) than the SRDOM and (2) there is only a slight (c. 5 percent) suppression of Eu sorption at higher $\mathrm{pH}$ values for the CDP, whereas, the suppression for the SRDOM is about 30 to 40 percent at the same organic matter content.

\subsubsection{CDP Temporal Effects}

The influence temporal changes in CDP character on Eu sorption were evaluated in a series of batch experiments using laboratory-generated CDP from week 6 and 19 at 10 and $30 \mathrm{mg} \mathrm{C/L}$. No temporal effects were observed for CDP generated in static-leaching tests for 6 and 19 weeks at either 10 or $30 \mathrm{mg}$ $C / L$ organic matter (see Figures $9 a$ and $9 b$ and Figures $9 c$ and $9 d$ ).

\subsubsection{Sorption Kinetics}

The results of the kinetic study of Eu sorption to SRS soil showed there to be 100 percent sorption at a time of 5 hours (Figure 12).

\subsection{Conclusions - Radionuclide Partitioning Studies}

As was shown in previous work, $\mathrm{pH}$ is the major determinant in the sorption of Eu to SRS soils in the presence or absence of CDP. This behavior can be largely explained by the electrostatic interactions between the cation in solution and sorption surface with $\mathrm{pH}$ dependant change.

In the presence of NOM or CDP, the concentration of organic matter, Eu concentration, and the source of the organic matter affect the sorption of Eu to SRS soils. 
The effects of organic matter concentration and $\mathrm{pH}$ on Eu sorption (i.e., decreased mobility) are summarized below:

\begin{tabular}{lcl}
\multicolumn{2}{c}{ SRDOM } & CDP \\
Low Organic & High Organic & Low Organic \\
\hline no effect & $\Uparrow$ sorption & no effect \\
slight $\Downarrow$ sorption & $\Downarrow$ sorption & slight $\Downarrow$ sorption
\end{tabular}

The concentration of Eu did not significantly affect its fractional sorption over the concentration range studied in this experiment. However, the data can be used to gain insight into the binding mechanism. Clark et al. (1998) reported that an increasing $\mathrm{pH}$ resulted in a decrease in slope of the isotherms, as evidence for a change in adsorption mode in the $\mathrm{pH}$ range of 3-5. In the current study, increasing $\mathrm{pH}$ resulted in an increase in slope of the isotherms. This supports the presence of only one absorption mode. Further evidence lies in the shape of the sorption edge in the absence of OM. The Clark et al. (1998) data showed two distinct absorption regions of the sorption edge, while the data in this study show only one absorption mode. However, the range of Eu concentrations in the Clark et al. (1998) study was much greater than in this study.

Laboratory-generated CDP and the Suwannee River of organic matter source had similar affects on Eu sorption at low-pH values and OM concentrations of 10 and $30 \mathrm{mg} \mathrm{C/l}$. At high-pH values, however, SRDOM decreased Eu sorption to SRS soil more than laboratory generated CDP. This is thought to be due to the formation of stronger Eu complexes with SRDOM due to its greater oxidation. This will be evaluated once acid-base titration data are available for the laboratory-generated CDP.

The results of the kinetic study indicate that the overnight equilibration times used in this study were long enough for the Eu to achieve equilibrium between the solid and solution phases.

There was no loss of Eu to the tube walls. Mass balance was completed between the solution phase and solid phase with an average recovery of 102 percent. 


\section{Phase II - Model Validation}

\subsection{Purpose and Approach - Model Validation}

This study has been completed to evaluate the assumptions and data used in the previous modeling work. This work evaluated the quantity, character, fate, and of CDP on Eu sorption to SRS soils.

\subsection{Previous Work - Model Validation}

Because of the lack of site-specific data and difficulties in modeling the chemical composition of CDP (a complex mixture of compounds), it was necessary to simplify the representation of CDP through use of surrogate organic compounds in the modeling effort. It was assumed that cellulose materials degrade to constantly produce DOC at $30 \mathrm{mg} \mathrm{C} / \mathrm{L}$. A source concentration of $79 \mathrm{mg} / \mathrm{L}$ citrate $(30 \mathrm{mg} \mathrm{C} / \mathrm{L})$ was selected based on dissolved organic matter production from a simulated waste-form containing approximately 40 percent wood products (Serne et al., 1993). This DOC was then available to react with other components in the model system (e.g., major ions, nuclides, and soil surfaces).

Citrate was selected as a surrogate for OM because it is a hydroxy-carboxylic acid typical of cellulose degradation products (Baston et al., 1992) and stability constants for reaction complexes between citrate and numerous radionuclides are available in the open literature. Additionally, citrate is expected to exhibit behavior similar to acetic acid, a major product in the anaerobic degradation of creosote (Cozzarelli et al., 1994). Therefore, citrate is believed to be a reasonable analogue for cellulose degradation products.

Due to the lack of stability constants for reactions between citrate and $\mathrm{Pd}, \mathrm{PuO}_{2}$, and $\mathrm{Zr}$, ethylenedinitrilotetraacetic acid (EDTA) was used as a surrogate with these elements. EDTA was selected because stability constants for reaction complexes between EDTA and numerous radionuclides are available in open literature and it is a strong complexing agent and should, therefore, act as a conservative surrogate for CDP. A source concentration of $69 \mathrm{mg} / \mathrm{L}$ EDTA (30 $\mathrm{mg} \mathrm{C/L)} \mathrm{was} \mathrm{used.}$

\subsection{Results and Conclusions - Model Validation}

In the previous modeling work it was assumed that cellulose materials degrade to constantly produce $\mathrm{DOC}$ at $30 \mathrm{mg} \mathrm{C/L}$. It is clear from this laboratory work that the production of CDP is a dynamic process with concentrations over 1000 
$\mathrm{mg} \mathrm{C/l} \mathrm{having} \mathrm{been} \mathrm{observed} \mathrm{in} \mathrm{these} \mathrm{laboratory} \mathrm{experiments.} \mathrm{This} \mathrm{study} \mathrm{and}$ natural system analogues show that there is a significant temporal influence on rate of CDP production with production rates decreasing as a function of increased leaching time. Other factors, such as moisture content of the cellulosic source material and the frequency of leaching have been shown in natural system analogues to have a significant influence on the rate of dissolved organic carbon production. These factors have not been considered in the previous modeling exercise and should be incorporated, to the extent possible, in future modeling efforts.

In the previous modeling effort a single $\mathrm{pH}$-value equal to the natural background level was used to estimate contaminant sorption. Consistent with the behavior of organic matter in terrestrial systems, is a lowering of the aqueous-phase $\mathrm{pH}$ during the cellulosic degradation process. Because the sorption of many nuclides and heavy metals to soil surfaces is very sensitive to small pH changes in the $\mathrm{pH} 4$ to 7 range, it is thought that the degradation of cellulosic materials could increase the mobility of these contaminants by reducing the $\mathrm{pH}$ of the system near the source of these cellulosic materials. Because of the strong dependence of metal/nuclide sorption on $\mathrm{pH}$, the influence of $\mathrm{pH}$ changes induced by the degradation of cellulosic materials should be considered in future modeling efforts.

Citrate was selected as a surrogate for $\mathrm{OM}$ in the previous modeling work. While this hydroxy-carboxylic acid provides a reasonable estimate of metal/nuclide complexation, its sorption behavior is considerably different from CDP. Over the range of geochemical conditions expected in the trench disposal environment the Suwannee River OM exhibits very similar behavior to CDP both in terms of sorption to SRS soils and in its affect on Eu binding. A large number of stability constants for aqueous-phase complexation have been generated for this material. Given the presence of these data and the fact that this surrogate will provides a more accurate representation of both aqueous complexation and soil surface sorption, it is recommended that future CDP modeling be conducted with data from this material or other natural organic matter.

One of the greatest uncertainties in modeling the fate of CDP as they move through the subsurface is the source concentration of CDP. We know that the system is quite dynamic and that in laboratory static-leach experiments CDP concentrations of over $1000 \mathrm{mg} \mathrm{C/l}$ were observed. In the previous modeling effort, however, a constant concentration of $30 \mathrm{mg} \mathrm{C/L}$ was assumed. Unlike the other aspects of this modeling where large data sets are available for natural organic matter analogues, little work has been conducted on the microbial degradation of DOC in groundwater. From the field studies, there is evidence that DOC should be retained by our soils and degraded quickly. No experimental data for these processes were generated in this study and the lack of natural system analogue data make this model input parameter highly uncertain. 
In conclusion, data on the sorption of CDP and its surrogate to SRS soils are available and should be considered in the next round of modeling. Because of the chemical similarities between laboratory-generated CDP and the Suwannee River CDP surrogate it is recommended that where data are available in literature for the interactions of these materials with nuclides/metals of interest they should be used in the modeling. It is further recommended that laboratory or field data be generated on the fate of CDP in SRS slit trench environments and these experiments be used to generate model input on CDP degradation rates.

\section{Summary and Conclusions}

Degradation products of cellulosic materials (e.g., paper and wood products) can significantly influence the subsurface transport of metals and radionuclides. Codisposal of radionuclides with cellulosic materials, for example in the E-Area slit trenches at the SRS, is therefore, expected to influence nuclide fate and transport in the subsurface.

In a previous modeling activity, significant differences in the allowable radionuclide inventory of the E-Area slit trench were determined when the presence of cellulose degradation products (CDP) was accounted for in the conceptual model. For example, the allowable inventory of U-233 and Pu-240 were calculated to be 26 percent and 48 percent lower, respectively, when CDP was present.

A series of studies were initiated to validate and/or update the modeling assumptions and results from the previous modeling effort. The first phase of this validation effort employed a well studied surrogate organic matter (OM) source, Suwannee River organic matter, to represent the influence of CDP generated as a result of disposal of cellulose-based materials in trenches on nuclide sorption to General Separation Area (GSA) soils. In particular, the sorption of the trivalent lanthanide $\mathrm{Eu}^{3+}$ and the divalent actinide $\mathrm{UO}_{2}{ }^{2+}$ to SRS soils or clays prevalent at SRS in the presence of this CDP surrogate was examined in a series of laboratory experiments. These multivalent cations were chosen for further study because previous modeling of this system (Serkiz and Myers, 1996) predicted that CDP would have the greatest influence on their mobility.

The Phase I study demonstrated that both $\mathrm{pH}$ and organic matter concentration had a significant influence on europium and uranium sorption and, hence mobility, in SRS shallow waste burial environments. Even in the absence of organic matter, the sorption of uranyl and $\mathrm{Eu}$ (III) is nonlinear with respect to $\mathrm{pH}$, and small $\mathrm{pH}$ changes in some regions caused very large changes in sorption and $K_{d}$ values. 
Phase II, the subject of this report, was designed to investigate major processes that influence nuclide transport in the presence of CDP; including the affects of 1) CDP characteristic (or CDP properties), 2) CDP fate, and 3) nuclide partitioning in the presence of CDP. These data were then compared to the current model input and recommendations made regarding the modeling of CDPcontaining systems.

The results of this Phase II study showed the following:

\section{CDP Characteristic}

Production of organic matter from cellulosic materials is very dynamic with dissolved organic carbon contents of over $1000 \mathrm{mg} \mathrm{C/L}$ being observed in our laboratory experiments. These dissolved organic carbon concentrations are consistent with values reported from studies of the degradation of natural organic matter in terrestrial environments (e.g., leaf litter degradation).

Also affected during the degradation process is a lowering of the aqueous-phase $\mathrm{pH}$. Because the sorption of many nuclides and heavy metals to soil surfaces is very sensitive to small $\mathrm{pH}$ changes, it is possible that the degradation of cellulosic materials could increase the mobility of these contaminants by reducing the $\mathrm{pH}$ of the system.

\section{CDP Fate}

This study confirmed the results of Phase I which showed that the sorption of the Suwannee River organic matter (CDP surrogate) to SRS soils is highly dependent on the system $\mathrm{pH}$ and the total concentration of organic matter. With lower $\mathrm{pH}$ and lower organic carbon content favoring greater fractional organic matter sorption.

At low-pH values and low organic carbon content, the sorption of both the CDP and SRDOM are similar. This is fortuitous, as this is in the range of $\mathrm{pH}$ values expected in SRS trench disposal environments, but the comparison can not be directly extended to higher $\mathrm{pH}$ regimes due to sorption differences between the CDP and Suwannee River organic matter.

\section{Nuclide Partitioning}

The presence of naturally occurring DOC or CDP, the concentration of organic matter, Eu concentration, and the source of the organic matter also affect the sorption of Eu to SRS soils. 
$\mathrm{DOC}$ concentration and $\mathrm{pH}$ had the greatest influence on Eu sorption (i.e, decreased mobility) and the results are summarized below:

\begin{tabular}{lll}
\multicolumn{2}{c}{ SRDOM } & CDP \\
Low Organic & High Organic & Low Organic \\
\hline no effect & $\Uparrow$ sorption & no effect
\end{tabular}

High pH slight $\Downarrow$ sorption $\Downarrow$ sorption slight $\Downarrow$ sorption

Laboratory-generated CDP and SRDOM had similar affects on Eu sorption at low-pH values and DOC concentrations of 10 and $30 \mathrm{mg} \mathrm{C/l}$. At high-pH values, however, SRDOM decreased Eu sorption to SRS soil more than laboratory generated CDP.

\section{Model Validation}

In an evaluation of the previous modeling approach, data on the sorption of CDP and its surrogate to SRS soils are available and should be considered in the next round of modeling. Because of the chemical similarities between laboratorygenerated CDP and the SRDOM, it is recommended that, where data are available in literature, stability constants generated from SRDOM or other natural organic matter be used in the modeling. It is further recommended that laboratory or field data be generated on the fate of CDP in SRS slit trench environments and these experiments be used to generate model input on CDP degradation rates. 


\section{References}

Allard B., Moulin V., Ballo L., Tran M.T. Stammose D., (1989). Americium Adsorption on Alumina in the Presence of Humic Materials. Geoderma, Vol.44, 181-187.

Averett, R. C.; Leenheer, J. A.; McKnight, D. M., and Thorn, K. A., eds. (1989). Humic Substances in the Suwannee River, Georgia: Interactions, Properties, and Proposed Structures. Denver, CO: U.S. Geological Survey; Open-File Report 87-557.

Baes C.F., Jr. and Mesmer R.E., (1986). The Hydrolysis of Cations. $2^{\text {nd }}$ ed. Robert E Krieger Publishing, Malabar, Fl.

Baston, G.M.N., Berry, J.A., Bond, K.A., Brownsword, M., and Linklater, C.M. (1992). Effects of Organic Degradation Products on the Sorption of Actnides. Radiochimica Acta, Vol. 58-59, 349-356.

Baston, G. M. N.; Berry, J. A.; Bond, K. A.; Boult, K. A.; Brownsword, M.; and Linklater, C. M. (1994). Effects of cellulosic degradation products on uranium sorpton in the geosphere. Journal of Alloys and Compounds. 213/214:475-480.

Baston G.M.N., Berry J.A., Bond K.A., Boult K.A., Linklater C.M. (1994) Effects of Cellulosic Degradation Product Concentration on Actinide Sorption on Tuffs From the Borrowdale Volcanic Group, Sellafield, Cumbria. Radiochim. Acta. Vol $66 / 67,521-526$.

Berry, J. A.; Bond, K. A.; Ferguson, D. R.; and Pilkington, N. J. (1991). Experimental Studies of The Effects of Organic Materials on the Sorption of Uranium and Plutonium. Radiochim. Acta. 52/53:201-209.

Bowles, E. C.; Antweiler, R. C., and MacCarthy, Patrick. (1989). Acid-Base Titration and Hydrolysis of Fulvic Acid From the Suwannee River in: Averett, R. C.; Leenheer, J. A.; McKnight, D. M., and Thorn, K. A., eds. Humic Substances in the Suwannee River, Georgia: Interactions, Properties, and Proposed Structures. Denver: U.S. Geological Survey; Open-File Report 87-557.

Choppin G.R. (1989). Soluble Rare Earth and Actinide Species in Seawater. Mar. Chem. Vol. 28, 19-26.

Clark S. B., Bryce A. L., Lueking, A., Gariboldi J., Serkiz S. M., (1998) Factors Affecting Trivalent f-element Adsorption to an Acidic Sandy Soil in Adsorption of Metals by Geomedia, Variables, Mechanisms, and Model Applications (E. A. Jenne, editor), Academic Press. 
Cozzarelli, I.M., Baedecker, M.J., Eganhouse, R.P., Goerlitz, D.F. (1994). The Geochemical Evolution of Low-Mocular-Weight Organic Acids Derived From the Degradation of Petroleum Contaminants in Groundwater. Geochimica et Cosmochimica Acta, Vol. 58, 863-877.

Dosskey, M. G. and Bertsch, P. M. (1997). Transport of dissolved organic matter through a sandy forest soil. Soil Sci. Soc. Am. J. 61(3):920-927.

Dunnivant, F. M.; Jardine, P. M.; Taylor, D. L.; and McCarthy, J. F. (1992). Transport of naturally-occurring dissolved organic carbon in laboratory columns containing aquifer material. Soil Sci. Soc. Am. J. 56(2):437-.

Edwards, M.; Benjamin, M. M.; and Ryan, J. N. (1996). Role of organic acidity in sorption of natural organic matter (NOM) to oxide surfaces. Colloids and Surfaces A: Physicochemical and Engineering Aspects. 107:297-307.

Fairhurst A.J., Warwick P., Richardson S. (1995). The Effect of pH on EuropiumMineral Interaction in the Presence of Humic Acid. Radiochim. Acta. Vol. 69, 103-111.

Findley, M. (1998) Characterizing the Environmental Availability of Trace Metals in Soils at the Savannah River Site. Master's Thesis. Clemson University, Clemson, SC.

Gintautas, P. A.; Huyck, K. A.; Daniel, S. R.; and Macalady, D. L. (1993). MetalOrganic Interactions in Subtitle $D$ Landfill Leachates and Associated Groundwaters. in: Allen, H. E.; Perdue, E. M.; and Brown, D. S., eds. Metals in Groundwater. Boca Raton, FL: Lewis; pp. 275-308.

Johnson, N.A. (1994). Clay Mineralogy of the Surficial Aquifer and Confining System, F- and H-Area Seepage Basins, Savannah River Site. Phase 1 - Final Report. University of Florida, Dept. of Geology.

Johnson, W. H. (1995) Sorption Models for U, Cs, and Cd on Upper Atlantic Coastal Plain Soils. Ph.D. Thesis. Georgia Institute of Technology, Atlanta, GA. Krauskopf, K. B. (1986). Thorium and Rare Earth Metals as Analogues for Actinide Elements. Chem. Geol. 55:323-335.

Khare, M. and Dondero, N. C. (1977). Fractionation and Concentration From Water of Volatiles and Organics on High Vacuum System: Examination of Sanitary Landfill Leachate. Environ. Sci. Technol. 11(8):814-819.

Ledin A., Karisson S., Düker A., Allard B. (1994). The Adsorption of Europium to Colloidal Iron Oxy-hydroxides and Quartz - The Impact of pH and an Aquatic Fulvic Acid. Radiochim. Acta, vol.66/67, 213-220. 
Lee J.J. and Weber D.E., (1979). Effects Of Sulfuric Acid Irrigation on Major Cation and Sulfate Concentration on Water Percolating through Two Model Hardwood Forests. J. Environ. Qual., Vol. 11, 57-64.

Lee H.B., Yeong J.P., Moon H., (1995). Identification Of Europium(III) Hydroxide Formation By Eu (III) Luminescence Spectroscopy. Bull. Korean Chem. Soc., Vol. 16, 654-657.

Leenheer, J. A.; Malcolm, R. L.; McKinley, P. W.; and Eccles, L. A. (1974). Occurrence of Dissolved Organic Carbon in Selected Groundwater Samples in the United States. U.S. Geological Survey Journal of Research. 2(3):361-369.

Malcolm, Ronald L.; Aiken, George R.; Bowles, E. C., and Malcolm, J. D. (1989). Isolation of Suwannee River Fulvic and Humic Acids in: Averett, R. C.; Leenheer, J. A.; McKnight, D. M., and Thorn, K. A., eds. Humic Substances in the Suwannee River, Georgia: Interactions, Properties and Proposed Structures. Denver: U.S. Geological Survey; Open-File Report 87-557.

Malcolm, Ronald L.; McKnight, Diane M., and Averett, R. C. (1989). History and Description of the Okefenokee Swamp-Origin of the Suwannee River in: Averett, R. C.; Leenheer, J. A.; McKnight, D. M., and Thorn, K. A., eds. Humic Substances in the Suwannee River, Georgia: Interactions, Properties and Proposed Structures. Denver: U.S. Geological Survey; Open-File Report 87557.

Mattigod, S.V., J.A. Frampton, and C.H. Lim, (1985) Effect of lon-Pair Formation on Boron Adsorption by Kaolinite, Clays and Clay Minerals, Vol. 33, 433-437.

McCarthy, J. F.; Williams, T. M.; Liang, L.; Jardine, P. M.; Jolley, L. W.; Taylor, D. L.; Palumbo, A. V.; and Cooper, L. W. (1993). Mobility of Natural Organic Matter in a Sandy Aquifer. Environ. Sci. Technol. 27(4):667-676.

Miller, R. W. and Gardiner, D. T. (1998). Soils in Our Environment. Upper Saddle River, NJ: Prentice Hall.

MMES (Martin Marietta Energy Systems), EG\&G Idaho, Inc., and Westinghouse Savannah River Company, (1994). Radiological Assessment for the E-area Vaults Disposal Facility (U). Report No. WSRD-RP-94-218, Rev. 0. WSRC, Aiken, SC.

Murphy, E. M. and Schramke, J. A. (1998). Estimation of Microbial Respiration Rates in Groundwater by Geochemical Modeling Constrained with Stable Isotopes. Geochim. Cosmochim. Acta. 62(21-22):3395-3406. 
Murphy, E.M., Zachara, J.M. and Smith, S.C. (1990). Influence of Mineral-Bound Humic Substances on the Sorption of Hydrophobic Organic Compounds. Environ. Sci. Technol., Vol.24, 1507-1516.

Murphy, E. M.; Zachara, J. M.; Smith, S. C.; and Phillips, J. L. (1992). The Sorption of Humic Acids to Mineral Surfaces and Their Role in Contaminant Binding. Sci. Total Environ. 117/118:413-423.

Noyes, T. I. and Leenheer, J. A. (1989). Proton Nuclear-Magnetic-Resonance Studies of Fulvic Acid From the Suwannee River in: Averett, R. C.; Leenheer, J. A.; McKnight, D. M., and Thorn, K. A., eds. Humic Substances in the Suwannee River, Georgia: Interactions, Properties, and Proposed Structures. Denver, CO: U.S. Geological Survey; Open-File Report 87-557.

Perdue, E.M. and Gjessing, E.T. (1990). Dahlem Workshop Reports: Organic Acids in Aquatic Ecosystems. Wiley \& Sons, New York.

Qualls, R. G. and Haines, B. L. (1991). Geochemistry of Dissolved Organic Nutrients in Water Percolating through a Forest Ecosystem. Soil Sci. Soc. Am. J. 55:1112-1123.

Rabung, Th.; Geckeis, H.; Kim, J. I.; and Beck, H. P. (1998). The Influence of Anionic Ligands on the Sorption Behavior of Eu(III) on Natural Hematite. Radiochim. Acta. 82:243-248.

Reinhard, M.; Goodman, N. L.; and Barker, J. F. (1984). Occurrence and Distribution of Organic Chemicals in Tow Landfill Leachate Plumes. Environ. Sci. Technol. 18(12):953-961.

Samadfam, M.; Sato, S.; and Ohashi, H. (1998). Effects of humic acid on the sorption of Eu(II) onto kaolinite. Radiochim. Acta. 82:361-365.

Schunthless C.P., Huang C.P., (1990). Adsorption of Heavy Metals by Silicon and Aluminum Oxide Surfaces on Clay Minerals. Soil Sci. Soc. Am. J. Vol. 54, 679-668.

Serkiz S.M., (1991). Factors Affecting the Binding of Protons and Metal lons to Naturally Occurring Dissolved Organic Matter. Doctoral Thesis, Georgia Institute of Technology.

Serkiz S. M., Knaub D., and Uhal H., (1998). Phase I Nuclide Partition Laboratory Study Influence of Cellulose Degradation Products On the Transport of Nuclides from SRS Shallow Land Burial Facilities (U). Westinghouse Savannah River Company. WSRC-TC-98-00460. Aiken, SC. 
Serkiz S. M. and Myers J.L., (1996). Additional Information for E-area Vault Performance Assessment, Appendix I "Suspect Soil Performance Analysis" Results of Modeling the Effects of Organic Matter on the Mobility of

Radionuclides as it Relates to the Disposal of Wood Products in E-Area Slit Trenches. Westinghouse Savannah River Company. WSRC-TR-98-00049. Aiken, SC.

Serkiz S. M. and Perdue E. M., (1990) Isolation of Dissolved Organic Matter From the Suwannee River Using Reverse Osmosis. Wat. Res., 24, 911-916.

Serne, R.J., Conca, J.L., LeGora, V.L., Cantrell, K.J., Lindenmeier, C.W., Campbell, J.A., Amonette, J.E. and Wood, M.I. (1993). Solid-Waste Leach Characteristics and Contaminant-Sediment Interactions, Volume 1: Batch Leach and Adsorption Tests and Sediment Characterization. Report No. PNL-8889 Vol. 1. PNL, Richland, WA.

Spark K. M., Johnson B. B., Wells J. D., (1995). Characterizing Heavy-Metal Adsorption on Oxides and Oxy-hydroxides. Europe. J. of Soil Sci. Vol. 46, 621631.

Sposito, G. (1984) The Surface Chemistry of Soils. Oxford University Press: New York.

Strom, R. N. and Kaback, D. S. (1992). SRP Baseline Hydrogeologic Investigation: Aquifer Characterization. Groundwater Geochemistry of the Savannah River Site and Vicinity. Report No. WSRC-RP-92-450. WSRC, Aiken, SC.

Stumm W. and Morgan, J.J. (1981). Aquatic Chemistry. Wiley \& Sons, New York.

Taylor, H. E. and Garbarino, J. R. (1989). Occurrence and Distribution of Selected Trace Metals in the International Humic Substances Society's Standard and Reference Fulvic And Humic Acids Isolated From the Suwannee River in: Averett, R. C.; Leenheer, J. A.; McKnight, D. M., and Thorn, K. A., eds. Humic Substances in the Suwannee River, Georgia: Interactions, Properties and Proposed Structures. Denver: U.S. Geological Survey; Open-File Report 87557.

Thorn, Kevin A. (1989). Nuclear-Magnetic-Resonance Spectrometry Investigations of Fulvic and Humic Acids From the Suwannee River in: Averett, R. C.; Leenheer, J. A.; McKnight, D. M., and Thorn, K. A., eds. Humic Substances in the Suwannee River, Georgia: Interactions, Properties, and Proposed Structures. Denver, CO: U.S. Geological Survey; Open-File Report 87-557. 
Thurman, E.M. (1985). Organic Geochemistry of Natural Waters. Kluwer Academic, Hingham, MA.

Tipping, E. (1981). Adsorption by Goethite (Alpha-FeOOH) of Humic Substances From Three Different Lakes. Chem. Geology. 33:81-89.

Tipping, E. (1981). The Adsorption of Aquatic Humic Substances by Iron Oxides. Geochim. Cosmochim. Acta. 45:191-199.

Tipping, E. (1986). Some Aspects of the Interactions Between Particulate Oxides and Aquatic Humic Substances. Mar. Chem. 18:161-169.

Tipping, E. and Cooke, D. (1982). The Effects of Adsorbed Humic Substances on the Surface Charge of Goethite (alpha-FeOOH) in Freshwaters. Geochim. Cosmochim. Acta. 46:75-80.

Tipping, E. and Heaton, M. J. (1983). The Adsorption of Aquatic Humic Substances by Two Oxides of Manganese. Geochim. Cosmochim. Acta. 47:1393-1397.

Uhal H. T., (1996). Uranyl Sorption by a Mixed Kaolinite and Naturally Occurring Organic Matter System. Special project presented to the faculty at Clemson University, Clemson, SC. 
Figure 1-Cycling of Organic Matter in the Subsurface from Thurman, 1985.

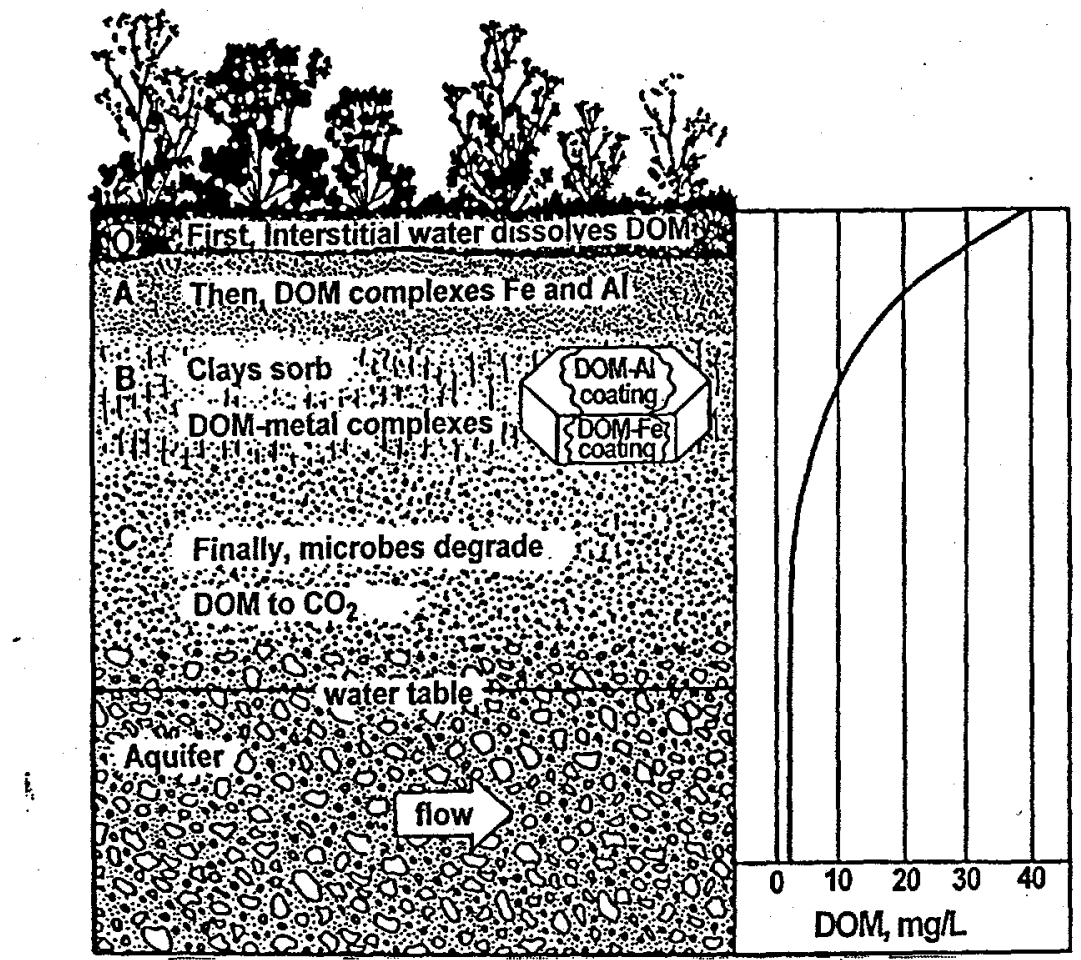

Figure 2 - Functional groups present on a complex DOC molecule from Thurman, 1985.

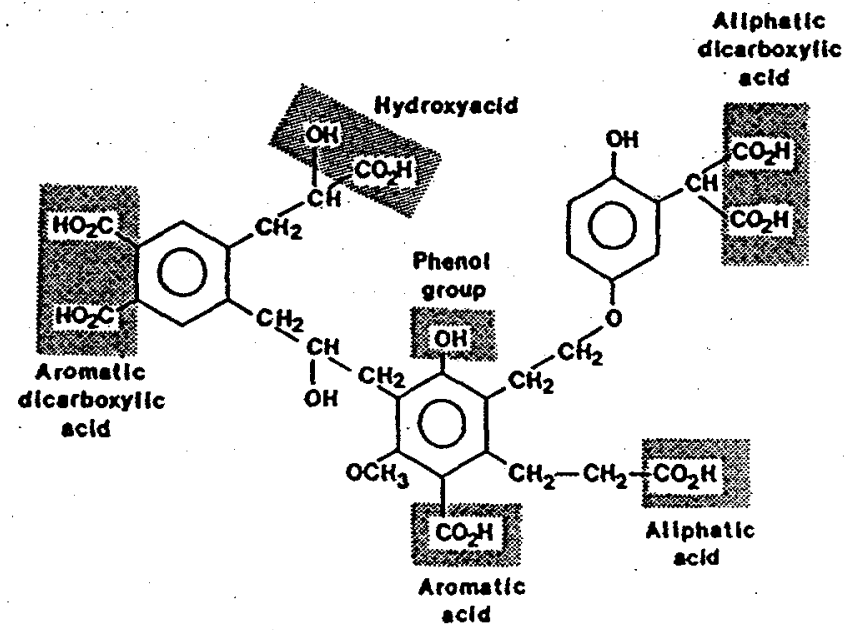


Figure 3-Structure of gluconate and iso-saccharinate.

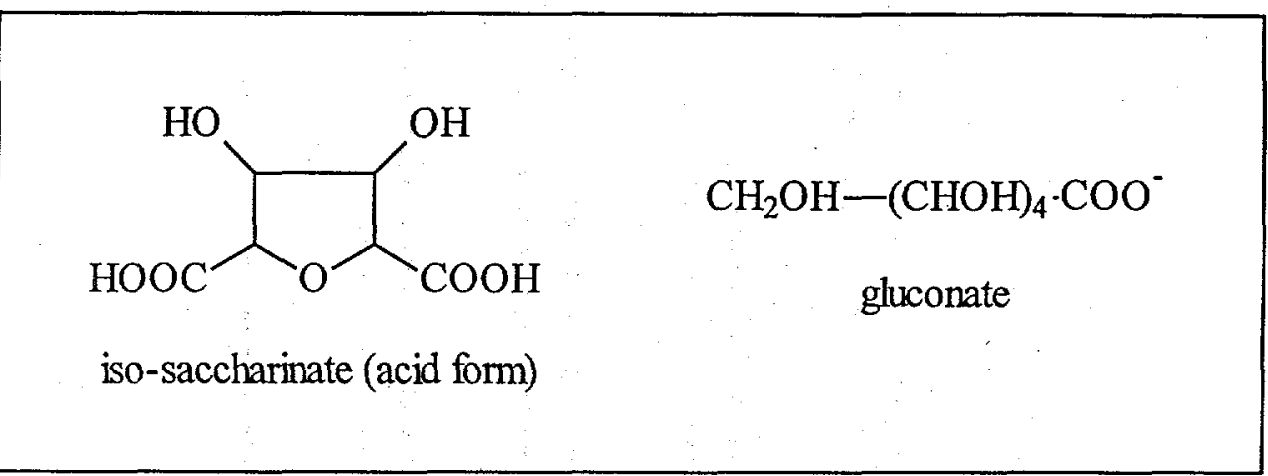

Figure 4-CDP Characterization

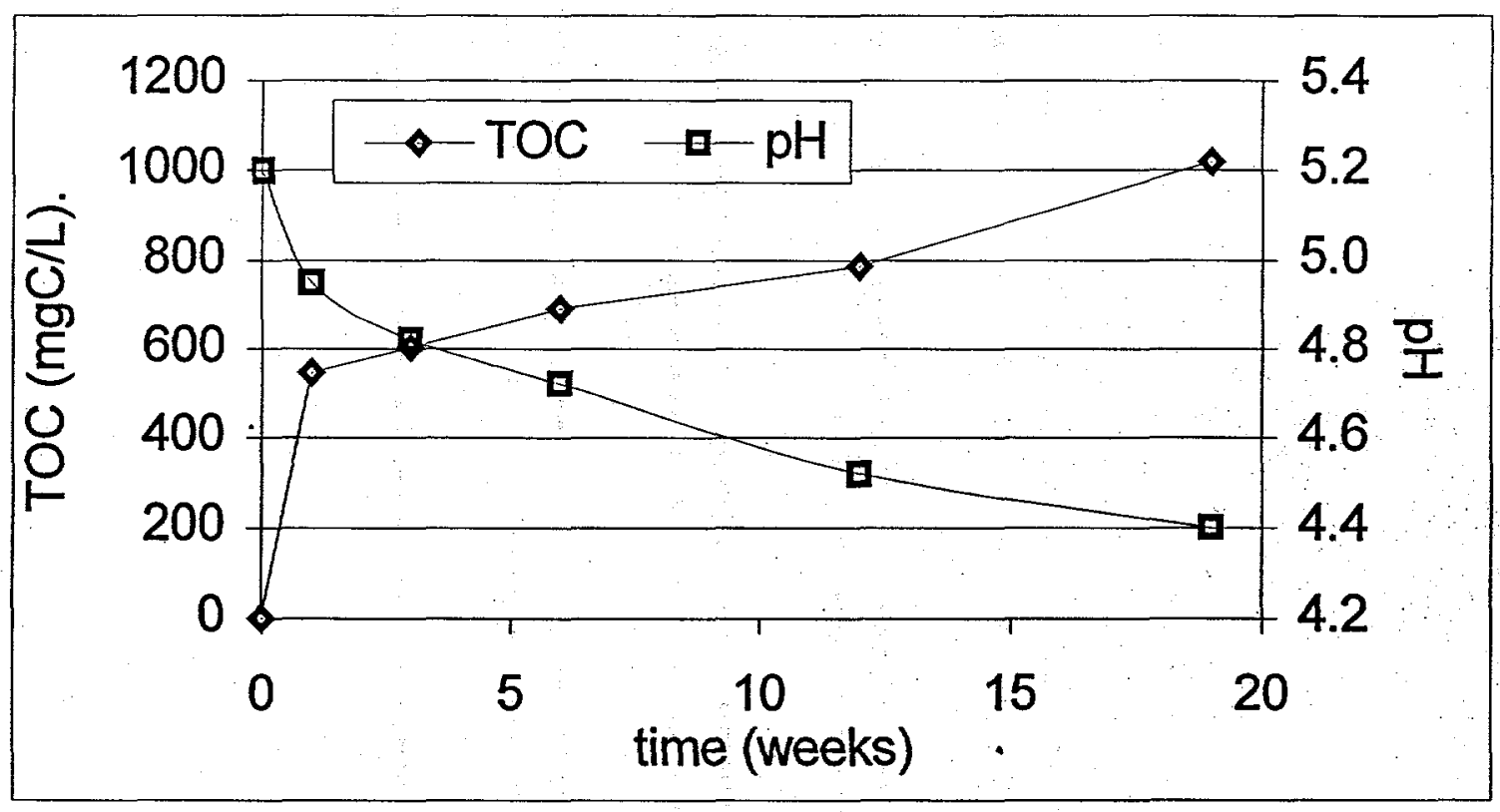


Figure 5-Effects of SRDOM Concentration on the Sorption of SRDOM to SRS Soil

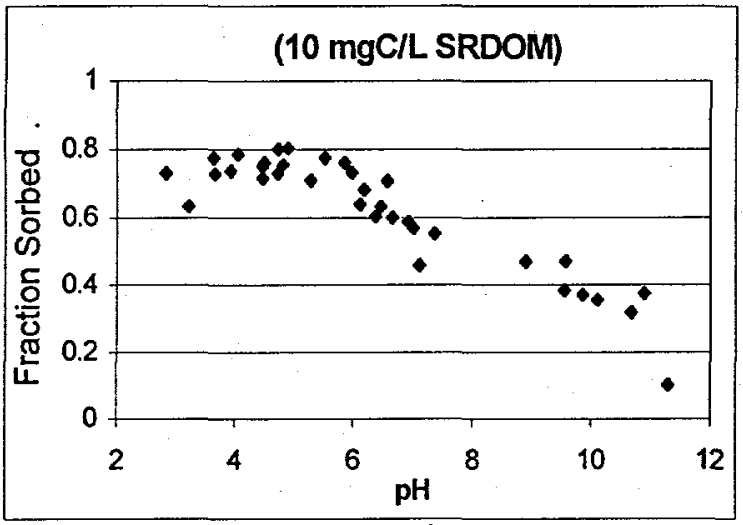

a.

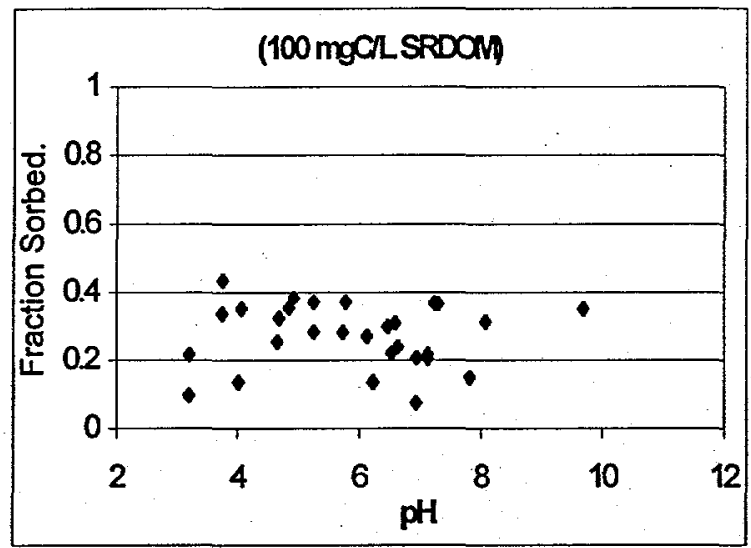

c.

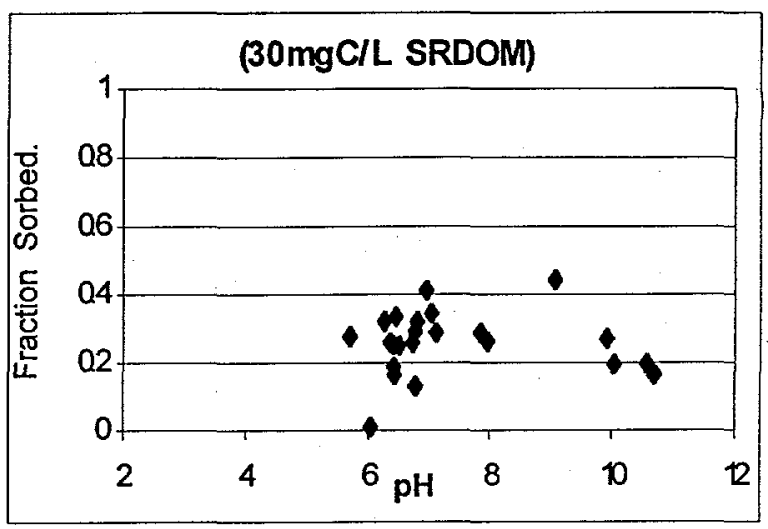

b.

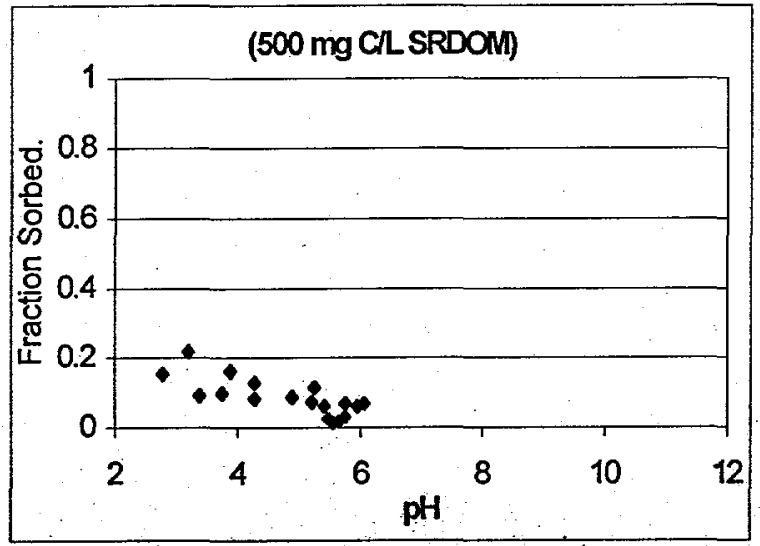

d. 
Figure 6 - Effects of Generation Time and CDP Concentration on the Sorption of CDP to SRS Soil

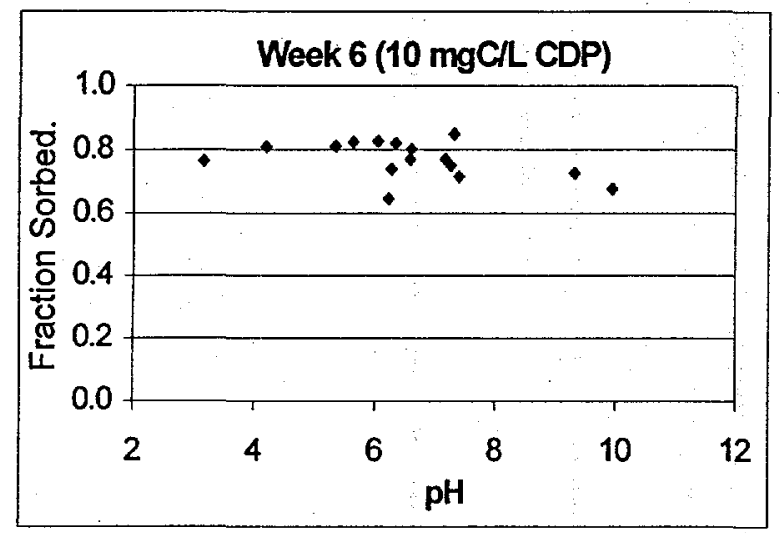

a.

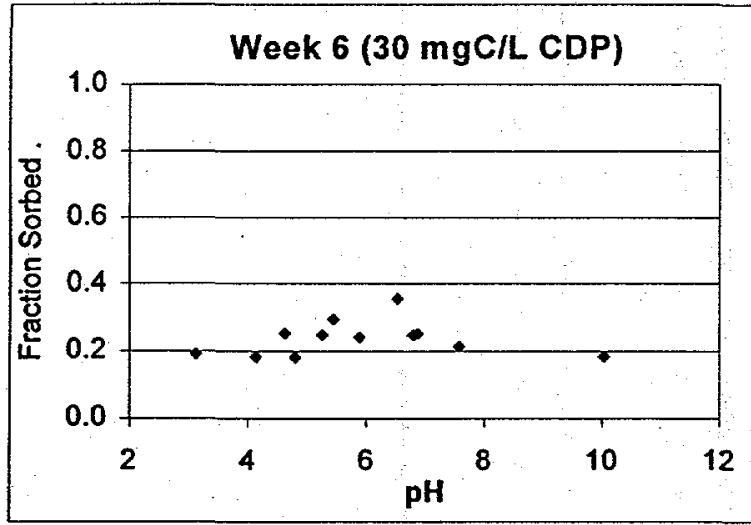

c.

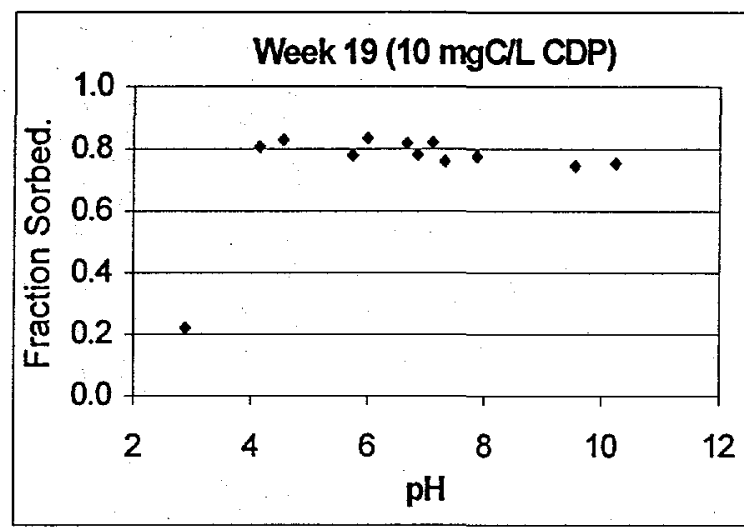

b.

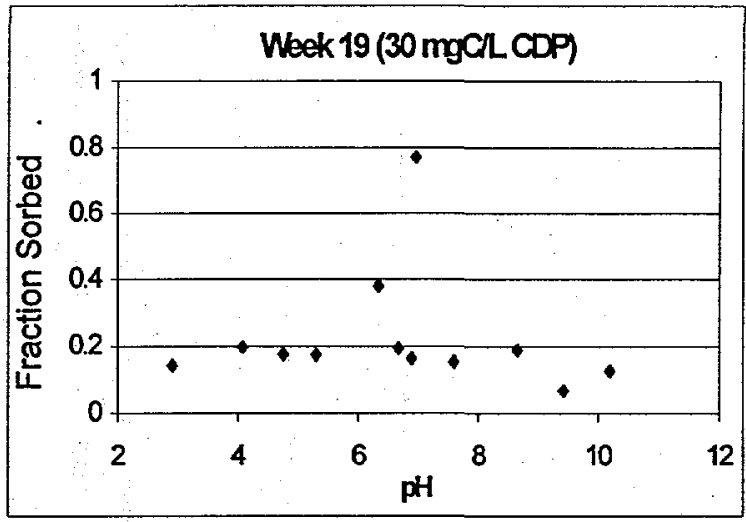

d.

Figure 7 - Sorption of Eu to SRS Soil ( $0 \mathrm{mgC/L}$ SRDOM)

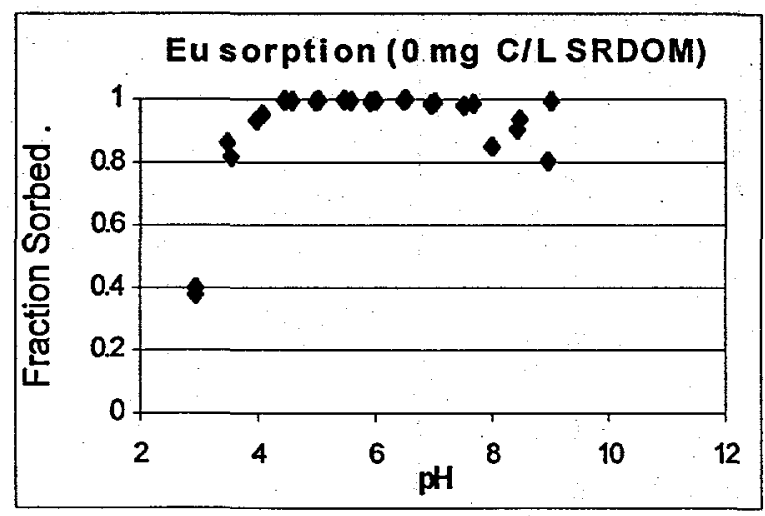


Figure 8 - Effects of SRDOM on the Sorption of Eu to SRS Soil

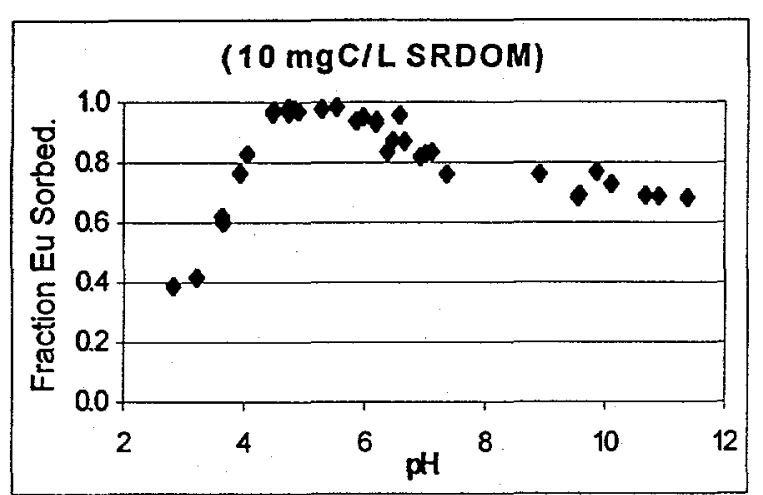

a.

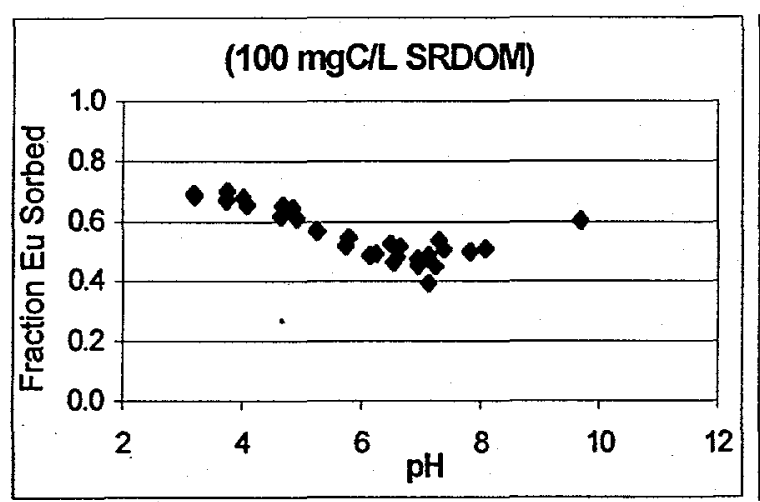

c.

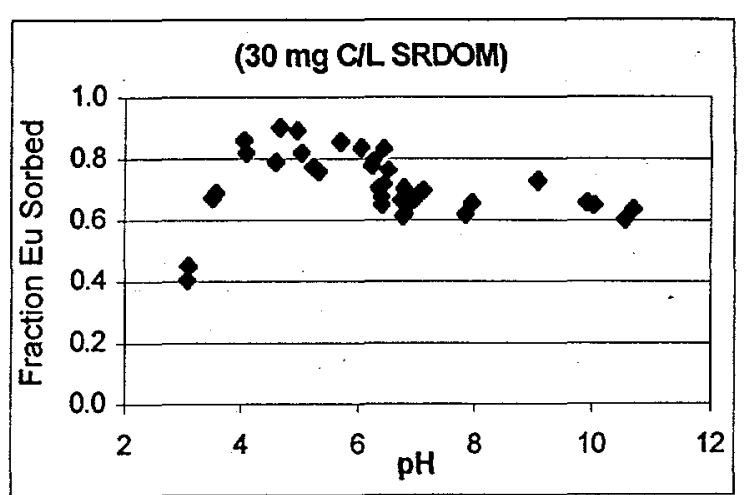

b.

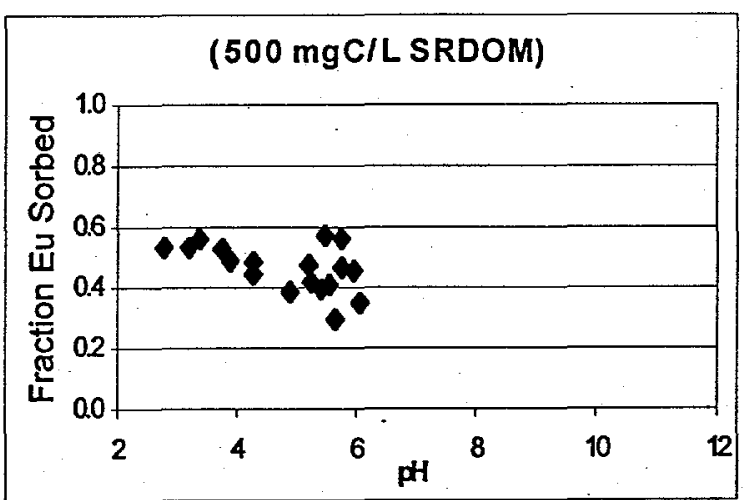

d. 
Figure 9 - Effects of Generation Time and CDP Concentration on the Sorption of Eu to SRS Soil

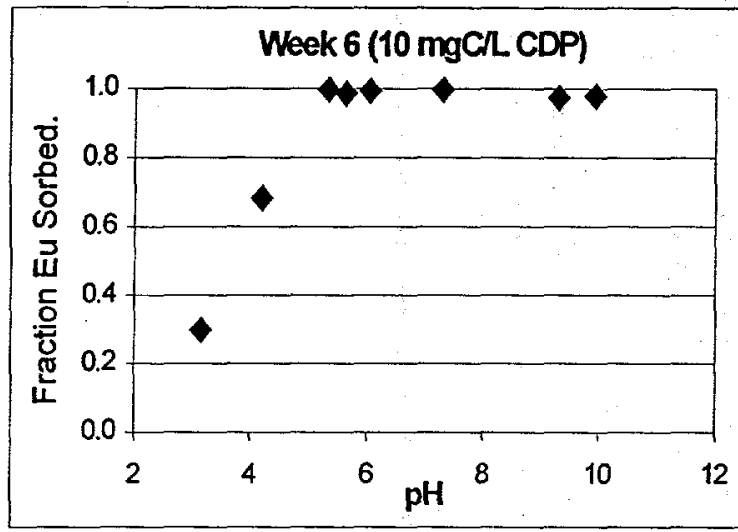

a.

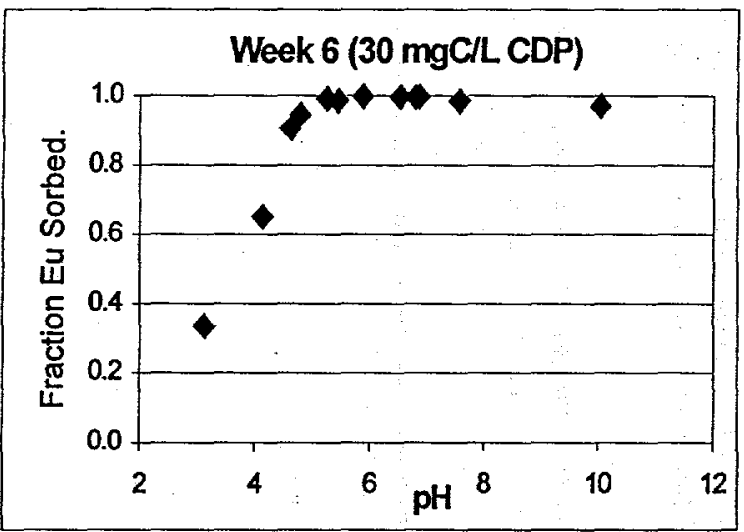

c.

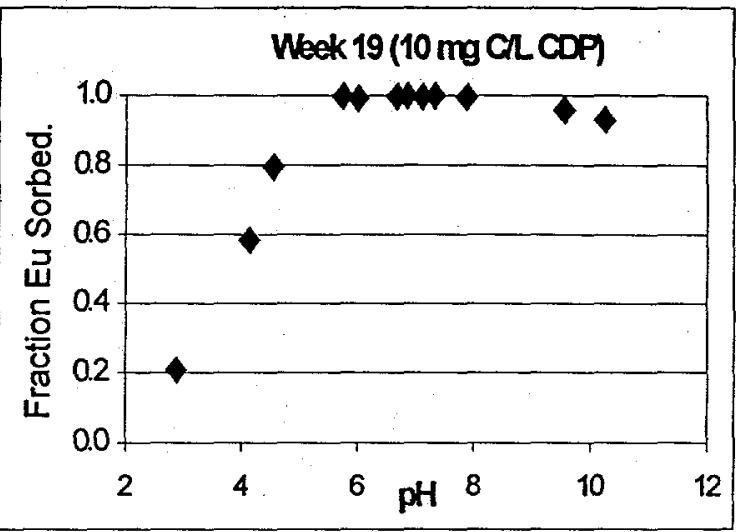

b.

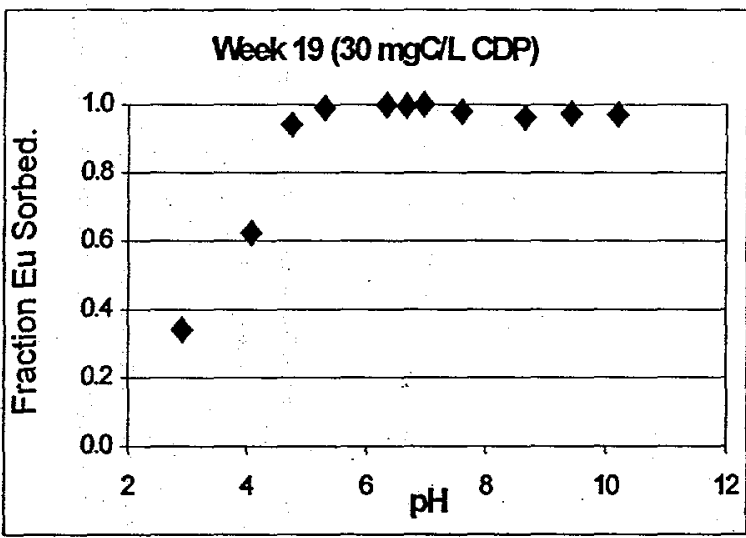

d.

Figure 10 - Sorption Isotherms for Eu on SRS Soil

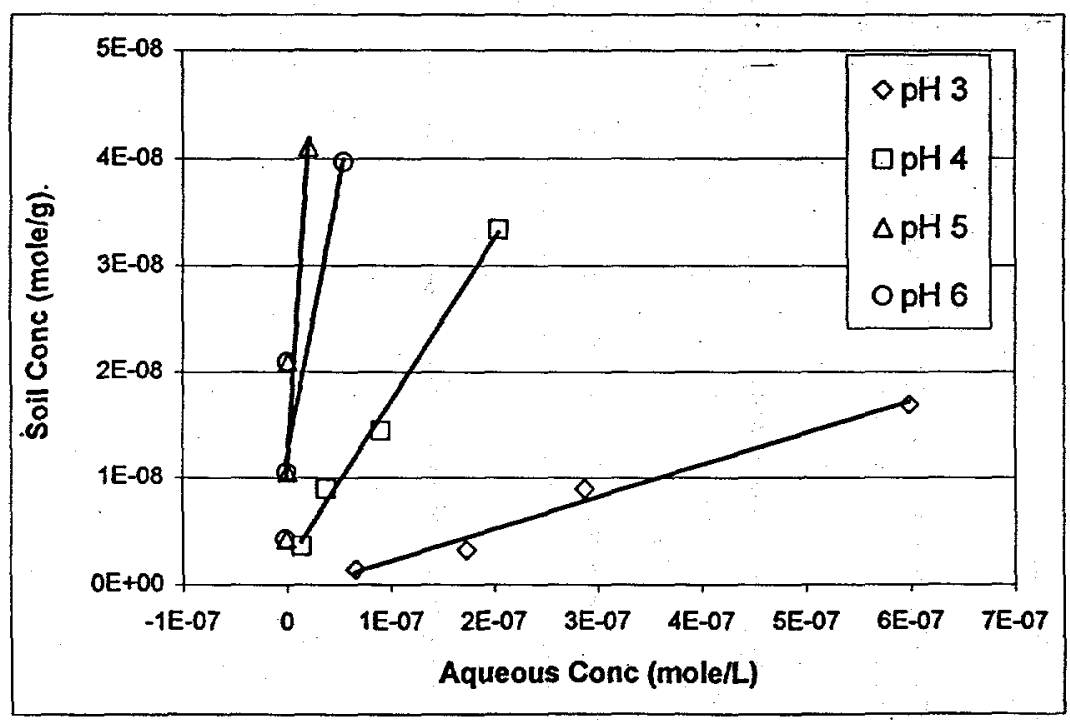


Figure 11- Effects of Organic Matter Source on Eu Sorption



a.

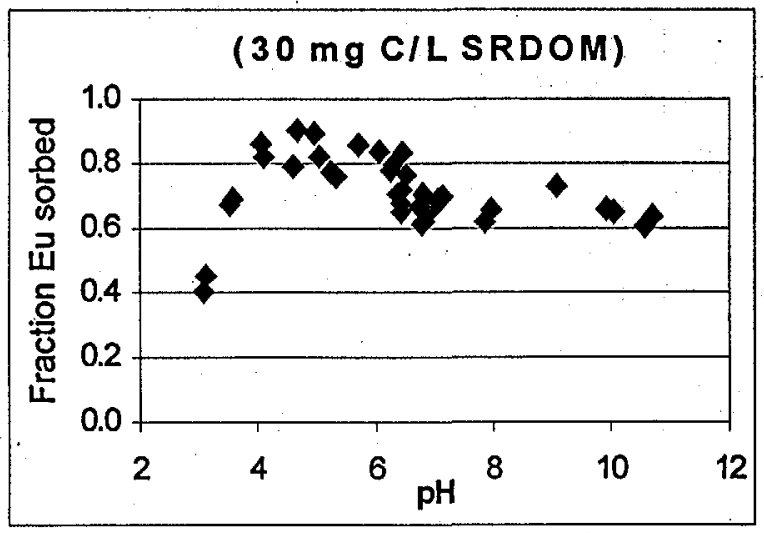

d.

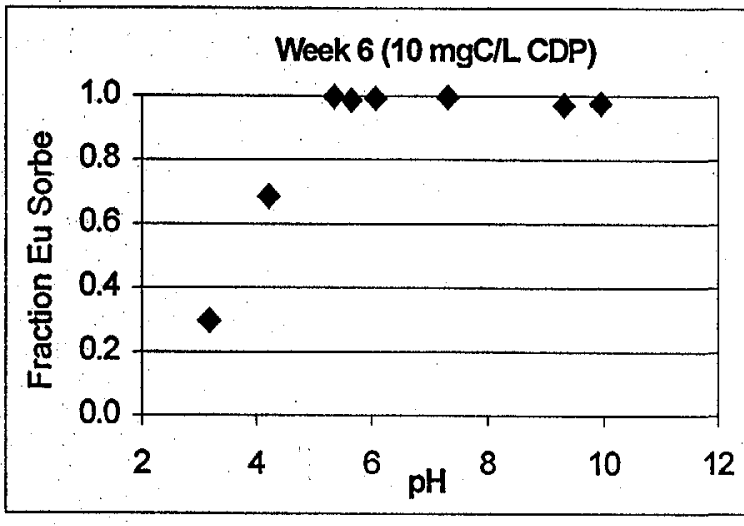

b.

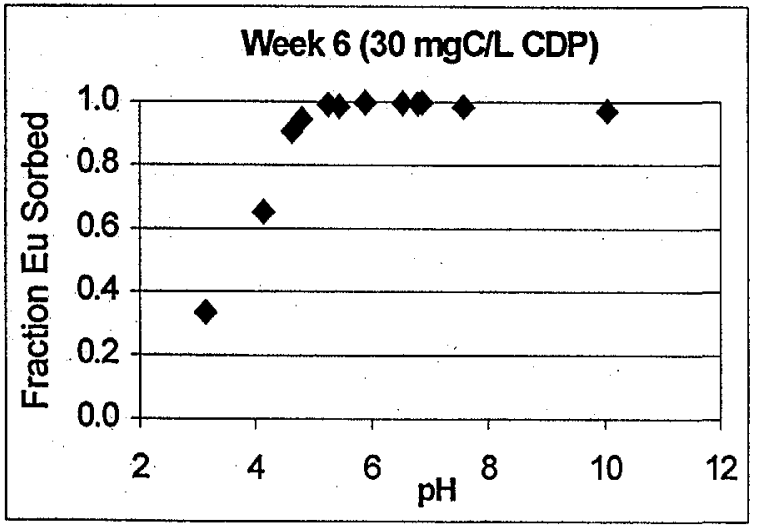

e.

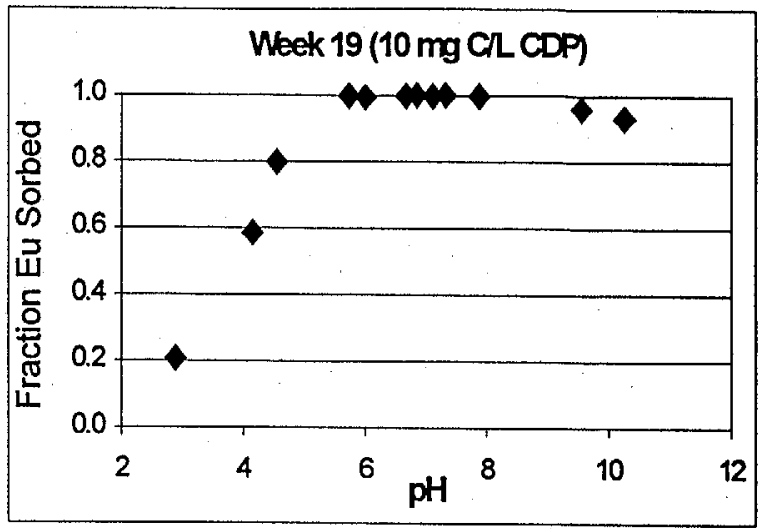

C.

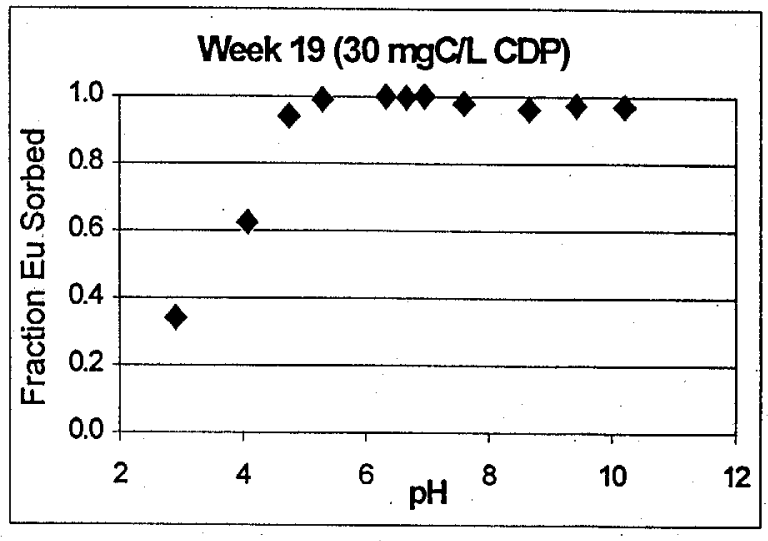

f. 
Figure 12 - Kinetics of Eu Sorption to SRS Soil

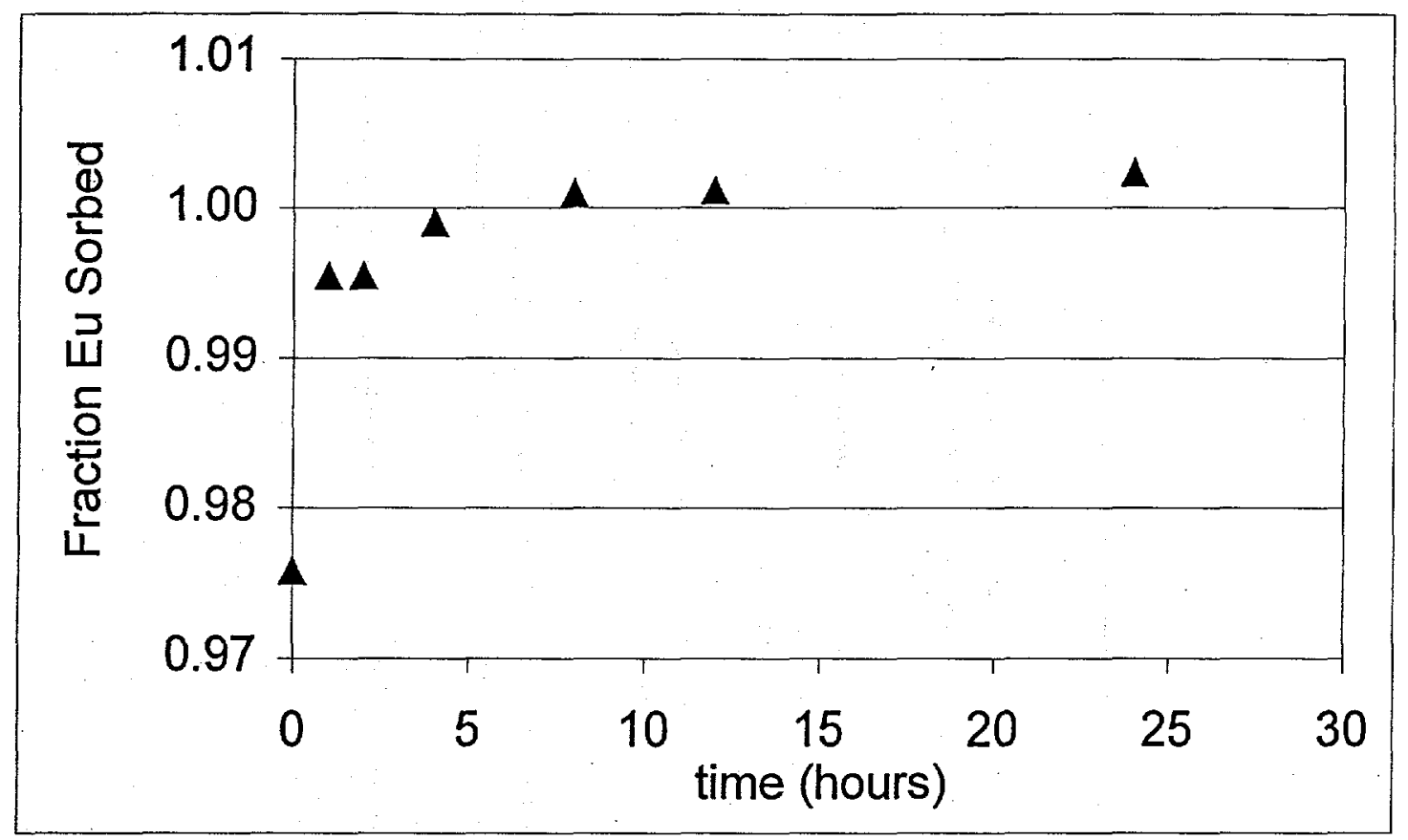

